\title{
Determination of aerosol properties from MAX-DOAS observations of the Ring effect
}

\author{
T. Wagner ${ }^{1}$, T. Deutschmann ${ }^{2}$, and U. Platt ${ }^{2}$ \\ ${ }^{1}$ Max-Planck-Institute for Chemistry, Mainz, Germany \\ ${ }^{2}$ Institute for Environmental Physics, University of Heidelberg, Germany
}

Received: 9 February 2009 - Published in Atmos. Meas. Tech. Discuss.: 9 March 2009

Revised: 11 June 2009 - Accepted: 23 August 2009 - Published: 4 September 2009

\begin{abstract}
The first quantitative comparison of MAX-DOAS observations of the Ring effect with model simulations is presented. It is performed for a large variety of viewing geometries (solar zenith angles: $45^{\circ}$ to $90^{\circ}$, elevation angles: $3^{\circ}, 6^{\circ}, 10^{\circ}, 18^{\circ}, 90^{\circ}$; three different azimuth angles), which allows a comprehensive test of our capabilities to measure and simulate the Ring effect. In addition to the Ring effect, also the observed $\mathrm{O}_{4}$ absorptions (optical densities) and radiances are compared with model simulations. In general good agreement is found for all measured quantities. From several sensitivity studies it is found that for most measurement situations, the aerosol optical depth has usually the strongest influence on the observed quantities, but also other aerosol properties like e.g. the vertical distribution have a significant effect. In some aspects, the qualitative dependence of the Ring effect on aerosol properties is similar to that of the $\mathrm{O}_{4}$ absorption. This can be understood, since both quantities depend strongly on the light path length in the lower atmosphere. However, since the Ring effect depends also on the properties of the scattering processes, in specific cases observation of the Ring effect can provide complementary information to that retrieved from the $\mathrm{O}_{4}$ observations. This is e.g. possible for measurements at small relative azimuth angles, from which information on the aerosol phase function can be derived. Observations at large solar zenith angle might allow the retrieval of stratospheric aerosol properties, even in cases with very low aerosol optical depths. In addition, Ring effect observations in zenith direction are rather sensitive to the aerosol optical depth (in contrast to $\mathrm{O}_{4}$ observations), which might allow to retrieve information on aerosol properties from existing zenith UV data sets prior to the MAX-DOAS era.
\end{abstract}

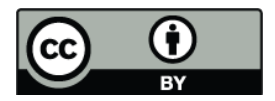

Correspondence to: T. Wagner (thomas.wagner@mpch-mainz.mpg.de)

\section{Introduction}

The Ring effect was first observed by Shefov (1959) and Grainger and Ring (1962); it describes the so-called "fillingin" of solar Fraunhofer lines in the spectra of scattered light compared to direct sun light observations and is caused by rotational Raman scattering by atmospheric molecules (Brinkmann, 1968; Kattawar et al., 1981; Solomon et al., 1987; Burrows et al., 1995; Chance and Spurr, 1997; Vountas et al., 1998). In many atmospheric remote sensing applications using scattered solar radiation (e.g. from ground based, airborne or satellite based observations), the accurate correction of the Ring effect is an important prerequisite for the precise retrieval of atmospheric trace gas absorptions (e.g. Noxon et al., 1979; Solomon et al., 1987; Chance and Spurr, 1997; Vountas et al., 1998; Sioris and Evans, 2000; Aben et al., 2001; de Beek et al., 2001; Wagner et al., 2002, 2004; Platt and Stutz, 2008). Usually, for that purpose a socalled Ring spectrum is calculated and included in the spectral fitting process; it can be obtained from observations using polarisation filters or can be computed from measured solar spectra (Solomon et al., 1987; Bussemer, 1993; Vountas, 1998; de Beek et al., 2001). In addition, the Ring effect reduces the optical densities of atmospheric trace gas absorption bands (Fish and Jones, 1995; Platt et al., 1997). Apart from the complicating effects of rotational Raman scattering on atmospheric trace gas retrievals, observations of the Ring effect can also be used to investigate details of atmospheric radiative transfer. Besides the viewing geometry and surface albedo, the filling-in of Fraunhofer lines depends on atmospheric scattering and thus on the presence and properties of clouds and aerosols. Thus, from the measured strength of the Ring effect, information on aerosols and clouds can be obtained (Park et al., 1986; Joiner et al., 1995, 2002, 2004; Joiner and Bhartia, 1995; de Beek et al., 2001; Wagner et al., 2004; Joiner and Vasilkov, 2006; van Deelen et al., 2008). In

Published by Copernicus Publications on behalf of the European Geosciences Union. 

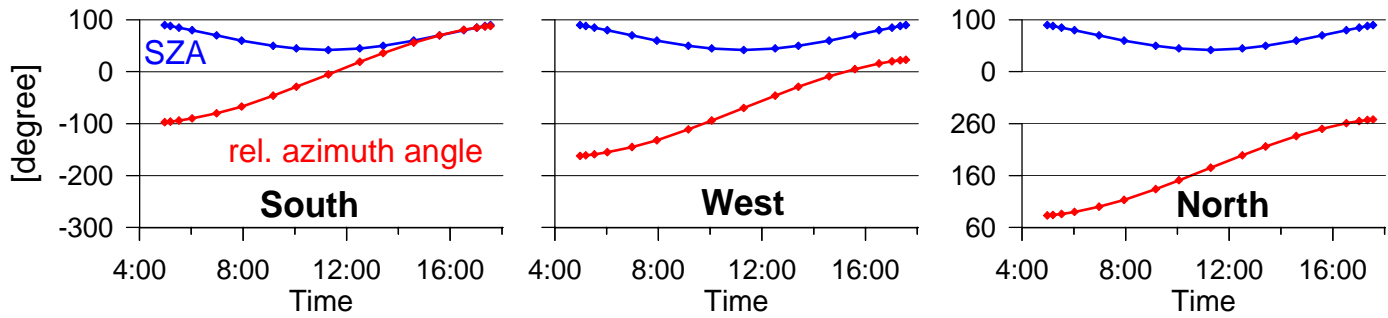

Fig. 1. Diurnal variation of the solar zenith angle (blue) and relative azimuth angle (red) for the three telescopes.

this study we focus on the potential to retrieve aerosol information from observations of the Ring effect using a ground based Multi-Axis-DOAS (MAX-DOAS) instrument. MAXDOAS instruments observe scattered sun light under a variety of elevation angles (Hönninger and Platt, 2002; Leser et al., 2003; Bobrowski et al., 2003; van Roozendael et al., 2003; Wittrock et al., 2004; Hönninger et al., 2004; Heckel et al., 2005; Wagner et al., 2004, 2007b; Frieß et al., 2006; Fietkau et al., 2007; Theys et al., 2007). The MAX-DOAS observations used in this study make simultaneous measurements in three different azimuth directions.

Recent studies have qualitatively and semi-quantitatively described the aerosol effect on ground based observations of scattered light (Wagner et al., 2004; Langford et al., 2007). Here we present the first comprehensive quantitative comparison of the observed and modelled Ring effect for MAXDOAS measurements on two cloud free days with very different aerosol loads. Our comparison includes a large variety of viewing conditions: the SZA ranges from about $45^{\circ}$ to $90^{\circ}$, the elevation angles include $3^{\circ}, 6^{\circ}, 10^{\circ}, 18^{\circ}$ and $90^{\circ}$ (zenith) and are made simultaneously at three different azimuth angles (North, West, South). The respective combinations of SZA and relative azimuth angles are shown in Fig. 1. In addition to the Ring effect, also the observed radiances and $\mathrm{O}_{4}$ absorptions are compared with model simulations, giving additional confidence both in the observations and model simulations.

Our paper is structured as follows: in Sect. 2, the instrument, data analysis, and observed quantities used in this study are introduced. In Sect. 3, the radiative transfer simulations are described. Section 4 shows the comparison of model simulations and measurements and in Sect. 5, the sensitivity of the Ring effect towards various atmospheric and surface parameters is investigated in detail.

\section{Measurements}

We investigate MAX-DOAS observations performed in September 2003 in Milan (Italy) during the FORMAT-II campaign (Formaldehyde as a tracer for oxidation in the troposphere (FORMAT) is a European research project, see www.nilu.no/format/). These observations were already discussed in a previous paper (Wagner et al., 2004) which fo- cussed on the aerosol effects on the $\mathrm{O}_{4}$ absorptions measured by MAX-DOAS. In this study, we focus on the aerosol influence on MAX-DOAS observations of the Ring effect. As a consistency check, we perform a simultaneous quantitative comparison also for the observed $\mathrm{O}_{4}$ absorptions as well as for the measured radiances. Our comparisons include two selected days (14 and 17 September 2003) with different aerosol load, which are mostly cloud free.

Since the MAX-DOAS observations are already described in detail in Wagner et al. (2004), here only a brief overview is given. The MAX-DOAS instrument observes light from three steerable telescopes, which are connected via glass fibre bundles to a spectrograph with a two-dimensional CCDdetector. The telescopes are directed at three different azimuth angles $\left(5^{\circ}, 185^{\circ}, 250^{\circ}\right)$ with respect to north. For simplicity we refer to these directions as north, south, and west, respectively. Each telescope sequentially scans 5 different elevation angles: $3^{\circ}, 6^{\circ}, 10^{\circ}, 18^{\circ}$ and $90^{\circ}$ (zenith); a single measurement is taken about every $90 \mathrm{~s}$ (a full sequence thus taking about $10 \mathrm{~min}$ ). The measurements cover the wavelength range $320-457 \mathrm{~nm}$ and the spectral resolution is about $0.75 \mathrm{~nm}$ (FWHM).

The $\mathrm{O}_{4}$ absorption and the Ring effect are analysed from the measured spectra in the wavelength range from 335$367 \mathrm{~nm}$ using the DOAS method (Platt and Stutz, 2008; Wagner et al., 2004). To remove the strong Fraunhofer structures, a measured spectrum taken at low SZA in zenith direction (a so-called Fraunhofer spectrum, FRS) is included in the fitting process. The Fraunhofer spectrum used in this study was measured at noon on 14 September 2003. In addition to the trace gas cross sections for $\mathrm{O}_{3}, \mathrm{NO}_{2}, \mathrm{BrO}, \mathrm{HCHO}$, and $\mathrm{O}_{4}$, a normalised Ring spectrum (see Wagner et al., 2009) calculated from the FRS is included in the spectral analysis. The fit coefficient retrieved for this normalised Ring spectrum directly yields the fraction of the observed photons which have undergone a Raman scattering event. In the following we refer to this fraction as "Raman scattering probability" (RSP), see Wagner et al. (2009). The RSP is a universal quantity for the description of the Ring effect and is in particular independent of the spectral resolution of the instrument. The RSP is directly proportional to various definitions of the Ring effect, see Table 1 and Wagner et al. (2009). 
Table 1. Relationship between the Raman scattering probability (RSP), which is used in this study to quantify the strength of the Ring effect, and other definitions used in other studies.

\begin{tabular}{lllll}
\hline Study & Instrument \& spectral resolution & Wavelength & Definition of filling-in & Relationship to RSP \\
\hline Joiner et al. (1995) & SBUV $\sim 1.1 \mathrm{~nm}$ & $393.37 \mathrm{~nm}$ & Filling-in factor & $=$ RSP*0.74 \\
Joiner et al. (2004) & GOME $\sim 0.17 \mathrm{~nm}$ & $393.37 \mathrm{~nm}$ & Filling-in factor & $=$ RSP*2.92 \\
Joiner et al. (2006) & OMI $\sim 0.50 \mathrm{~nm}$ & $393.37 \mathrm{~nm}$ & Filling-in factor & $=$ RSP*1.79 \\
de Beek et al. (2001) & GOME $\sim 0.17 \mathrm{~nm}$ & $393.37 \mathrm{~nm}$ & Ring DOD & $=$ RSP*3.02 \\
Langford et al. (2007) & Ground based $\sim 0.33 \mathrm{~nm}$ & $344.1 \mathrm{~nm}$ & Fractional filling-in & $=$ RSP*1.01 \\
\hline
\end{tabular}

The retrieved fit coefficient for the $\mathrm{O}_{4}$ cross section (for 296 K) (Greenblatt et al., 1990) yields the slant column density (SCD, the trace gas concentration along the absorption path). In the case of $\mathrm{O}_{4}$, the SCD cannot be directly referred to $\mathrm{O}_{4}$, because the equilibrium constant between $\mathrm{O}_{4}$ and $\left(\mathrm{O}_{2}\right)_{2}$ is not known. Therefore usually the $\mathrm{O}_{4} \mathrm{SCD}$ is referred to the integrated quadratic $\mathrm{O}_{2}$ concentration (see also Greenblatt et al., 1990). The $\mathrm{O}_{4} \mathrm{SCD}$ then includes the equilibrium constant and it has the unit $\left[\mathrm{molec}^{2} / \mathrm{cm}^{5}\right]$. From the comparison between measurements and model results, it was found that the retrieved $\mathrm{O}_{4}$ SCDs were systematically too high to match the model simulations: On the day with low aerosol load (14 September 2003), the measured values were found to be even larger than the simulations for a pure Rayleigh atmosphere. One reason for this discrepancy is probably the temperature dependence of the $\mathrm{O}_{4}$ absorption at $360 \mathrm{~nm}$ (see e.g. Wagner et al., 2002). The atmospheric temperature at the measurement site weighted with the $\mathrm{O}_{4}$ profile was about $267 \mathrm{~K}$ compared to $296 \mathrm{~K}$ for the laboratory measurement of the $\mathrm{O}_{4}$ cross section.

The value of the $\mathrm{O}_{4}$ cross section used in this study $\left(5.27 \times 10^{46} \mathrm{~cm}^{5} / \mathrm{molec}^{2}\right)$ was determined from the detailed comparison between measurement and model results (see Sect. 4). This determination could be performed with an accuracy of about $10 \%$. The influence of other possible effects like e.g. spectrograph straylight or errors in the determination of the elevation angles could be largely ruled out, because they would have affected observations at different elevation and azimuth angles (see Sect. 4) in a different way. The value of the $\mathrm{O}_{4}$ cross section at $360 \mathrm{~nm}$ found from this comparison is close to the values found by Volkamer (1996) $\left(5.42 \times 10^{46} \mathrm{~cm}^{5} / \mathrm{molec}^{2}\right)$ and Perner and Platt (1980) $\left(5.4 \times 10^{46} \mathrm{~cm}^{5} / \mathrm{molec}^{2}\right)$.

Finally, the $\mathrm{O}_{4} \mathrm{SCDs}$ are converted into $\mathrm{O}_{4}$ air mass factors (AMF) to allow a direct comparison with the results from the radiative transfer simulations. AMF is defined as the ratio of the SCD and VCD (e.g. Solomon et al., 1987):

$$
\mathrm{AMF}=\mathrm{SCD} / \mathrm{VCD}
$$

VCD denotes the vertically integrated $\mathrm{O}_{4}$ column density.

The $\mathrm{O}_{4}$ VCD for both selected days were calculated from the atmospheric profiles of temperature and pres-

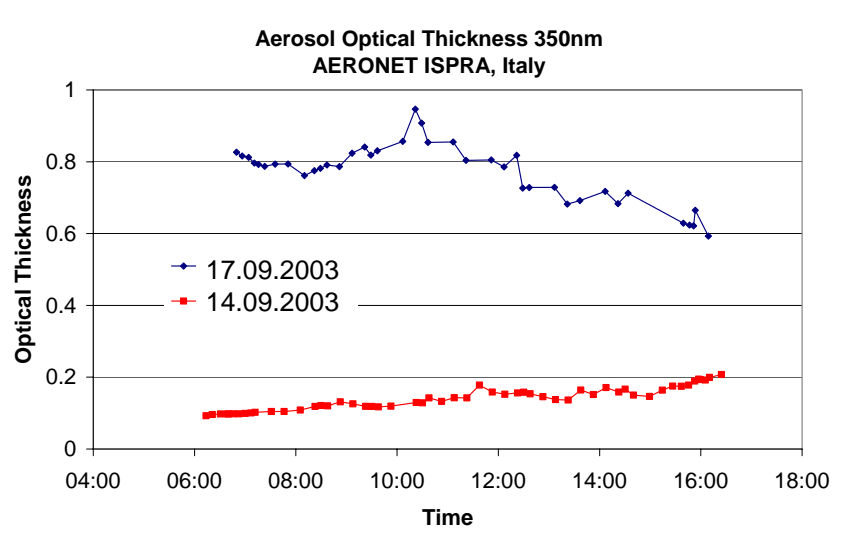

Fig. 2. Aerosol extinction at $350 \mathrm{~nm}$ measured by the AERONET station at Ispra (Principal Investigator: Giuseppe Zibordi). The distance between Ispra and the location of the MAX-DOAS measurements (Milan) is about $60 \mathrm{~km}$.

sure obtained from surface observations and model results (taken from the Air Research Laboratory, see http://www. ready.noaa.gov/ready.html) taking into account the elevation ( $130 \mathrm{~m}$ above sea level) of the measurement site. The $\mathrm{O}_{4}$ VCD changed only little for these days $( \pm 1 \%)$ and a value of $1.3 \times 10^{43} \mathrm{molec}^{2} / \mathrm{cm}^{5}$ is used for the conversion of $\mathrm{O}_{4} \mathrm{SCD}$ into $\mathrm{O}_{4} \mathrm{AMF}$. Note that this value is about $10 \%$ higher than in Wagner et al. (2004). The difference is caused by the use of the precise altitude profiles of pressure and temperature for both selected days in this study, whereas in Wagner et al. (2004) the altitude profiles were estimated from the surface values of temperature and pressure.

Since the Fraunhofer spectrum also contains atmospheric absorption structures of $\mathrm{O}_{4}$ (and other trace gases) and is also subject to the Ring effect, the result of the DOAS analysis represents the respective differences between the measured spectrum and of the Fraunhofer spectrum (often the results are referred to as differential SCD (DSCD) and differential AMF (DAMF)). The $\mathrm{O}_{4}$ absorption and the Ring effect of the Fraunhofer spectrum are estimated using radiative transfer simulations for an aerosol optical depth of 0.1 (similar to the aerosol optical depth on 14 September, see Fig. 2). The values of the $\mathrm{O}_{4} \mathrm{AMF}$ and $\mathrm{RSP}$ are $1.8 \pm 0.1$ and $0.05 \pm 0.01$, 
Ring effect, western telescope
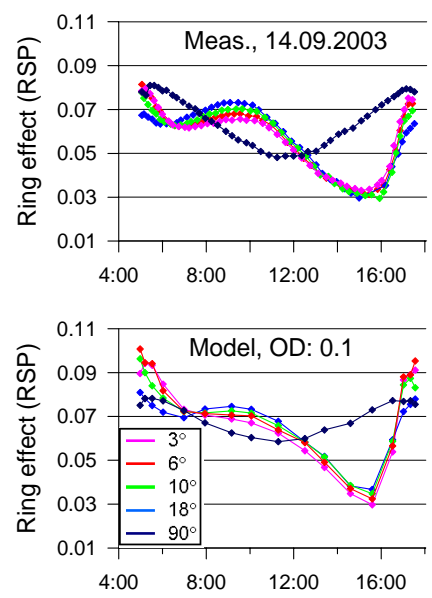

$\mathrm{O}_{4}$ absorption, western telescope
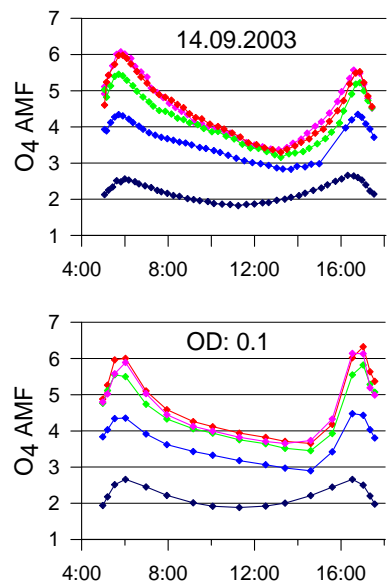
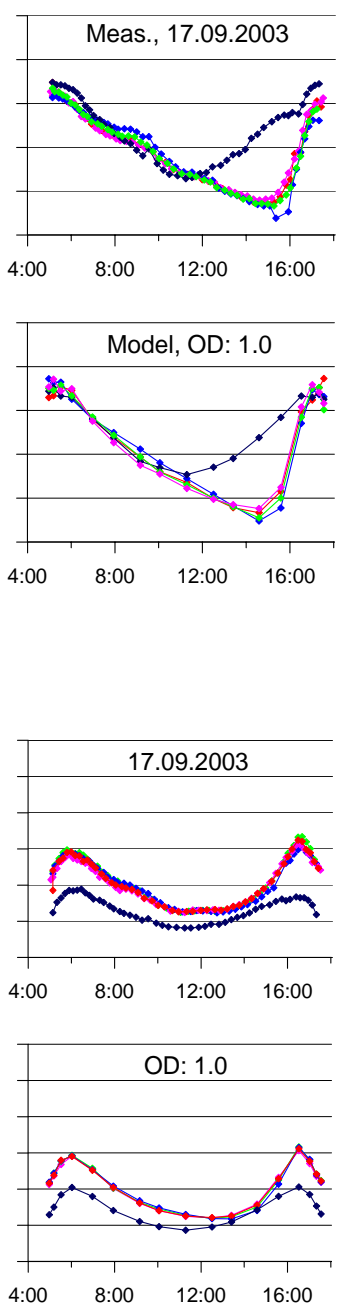

Radiance, western telescope
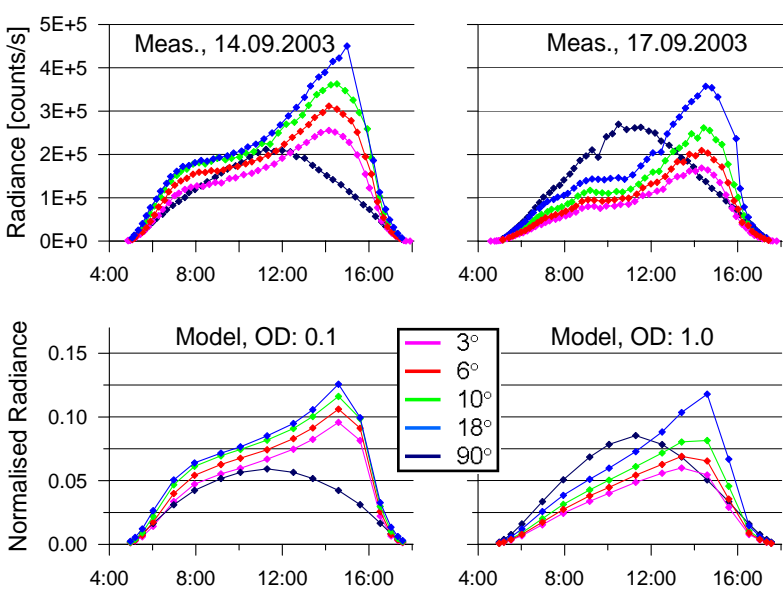

Radiance ratio, western telescope
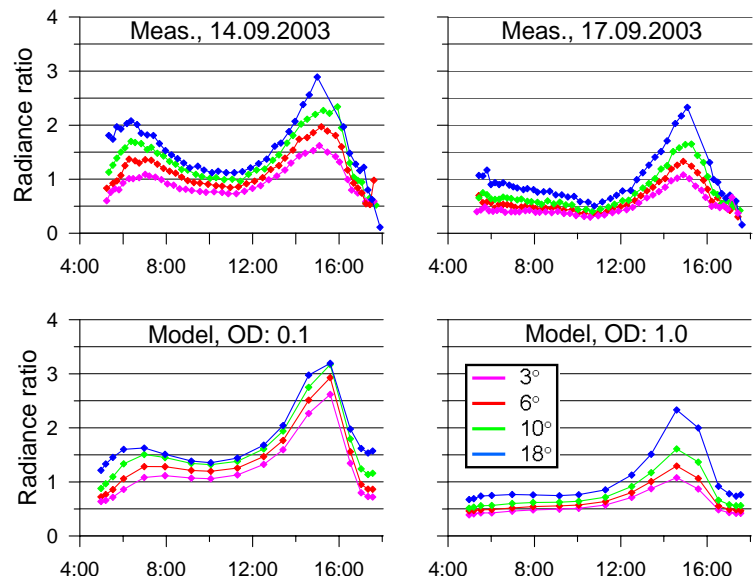

Fig. 3. Comparison of measurements and model results for the western telescope on two selected days (14 and 17 September 2003). Besides the Ring effect, also the $\mathrm{O}_{4}$ AMF and the measured radiance and radiance ratio are displayed. In each sub-plot the upper graphs show the measurement results for the 14 September 2003 (left) and 17 September 2003 (right); the lower graphs show model results for aerosol OD of 0.1 (left) and 1.0 (right). Further aerosol properties are: constant extinction between 0 and $1 \mathrm{~km}$, single scattering albedo of 0.9 , asymmetry parameter of 0.68 .

respectively. For the comparison between model results and measurements (Figs. 3, 4, 9, 10, and Appendix) these values for the $\mathrm{O}_{4} \mathrm{AMF}$ and the RSP of the Fraunhofer reference spectrum were added to the measurements.

Besides the $\mathrm{O}_{4}$ absorption and the Ring effect, also the observed radiance (at $350 \mathrm{~nm} \pm 1 \mathrm{~nm}$ ) is compared to the model simulations. Since the instrument is not radiometrically calibrated, the radiance is only used in relative units and no stringent comparison to model results is possible. Thus, in addition to the radiance itself, we also calculated radiance ratios with respect to the radiance of the measurement in zenith direction (of the same elevation sequence). This radiance ratio is independent of the radiometric calibration and can be di- rectly compared to the respective ratios from the model simulations. An overview of the measured quantities used in this study is given in Table 2 .

\section{Radiative transfer modelling}

In this study we use the full spherical Monte-Carlo atmospheric radiative transfer model McArtim (Monte Carlo Atmospheric Radiative Transfer and Inversion Model) (Deutschmann, 2008); it was compared to various other radiative transfer models (Wagner et al., 2007a) and excellent agreement was found. McArtim allows the simulation of ensembles of individual photon trajectories for a given 
Table 2. Overview of the quantities derived from the MAX-DOAS measurements and used in this study.

\begin{tabular}{|c|c|c|c|}
\hline Quantity & Wavelength & Definition & Remarks \\
\hline $\begin{array}{l}\text { Raman scattering } \\
\text { probability (RSP) }\end{array}$ & $350 \mathrm{~nm}$ & $\begin{array}{l}\text { The RSP is the fit coefficient of a } \\
\text { normalised Ring spectrum included } \\
\text { in the DOAS analysis (see Wagner } \\
\text { et al., 2009). The RSP is the prob- } \\
\text { ability of a photon to be Raman- } \\
\text { scattered. }\end{array}$ & $\begin{array}{l}\text { The RSP is proportional to various definitions of } \\
\text { the Ring effect (see Table 1) and is independent } \\
\text { from the spectral resolution. For the comparison } \\
\text { with model results, an offset of } 0.05 \text { (RSP of the } \\
\text { Fraunhofer reference spectrum) has to be added. }\end{array}$ \\
\hline $\begin{array}{l}\mathrm{O}_{4} \mathrm{AMF} \\
(\mathrm{DAMF})\end{array}$ & $360 \mathrm{~nm}$ & $\begin{array}{l}\text { The retrieved } \mathrm{O}_{4} \text { (differential) slant } \\
\text { column density is divided by the ver- } \\
\text { tical } \mathrm{O}_{4} \text { column density. }\end{array}$ & $\begin{array}{l}\text { For comparison with model results, an offset of } \\
1.8\left(\mathrm{O}_{4} \text { AMF of the Fraunhofer reference spec- }\right. \\
\text { trum) has to be added. }\end{array}$ \\
\hline Radiance & $350 \mathrm{~nm}$ & $\begin{array}{l}\text { Average of measured signal (counts } \\
\text { per second) at } 350 \pm 1 \mathrm{~nm} \text {. The in- } \\
\text { strument has no absolute radiometric } \\
\text { calibration. }\end{array}$ & $\begin{array}{l}\text { For the comparison with model results, the val- } \\
\text { ues are divided by a proportionality factor deter- } \\
\text { mined empirically from the best match between } \\
\text { measurements and model results }\end{array}$ \\
\hline Radiance ratio & $350 \mathrm{~nm}$ & $\begin{array}{l}\text { The radiance is divided by the radi- } \\
\text { ance of the zenith observation of the } \\
\text { same elevation sequence. }\end{array}$ & $\begin{array}{l}\text { The radiance ratio is independent from the abso- } \\
\text { lute radiometric calibration and can be directly } \\
\text { compared to the model results }\end{array}$ \\
\hline
\end{tabular}

atmospheric situation. From these trajectories the average frequency of the modelled photons for certain interactions with atmospheric constituents or with the Earth's surface are determined. The scattering events are modelled individually, according to their respective scattering cross sections and phase functions. Interaction with the Earth's surface is treated as a Lambertian reflection. In addition to elastic processes (the reflection at the surface, Rayleigh scattering at molecules, scattering on aerosol and cloud particles), also rotational Raman scattering events are modelled (for more details, see Wagner et al., 2009). From the output of the Monte Carlo simulations we determine the fraction of all observed photons, which have undergone a rotational Raman scattering event, by counting the numbers of RRS-scattered and total photons). This fraction represents the Raman scattering probability (RSP) as defined in Wagner et al. (2009) and can be directly compared to the results from the spectral analysis (see Sect. 2). In this study, the vertical discretisation was chosen to $50 \mathrm{~m}$ below $200 \mathrm{~m}, 200 \mathrm{~m}$ below $12 \mathrm{~km}, 1 \mathrm{~km}$ below $25 \mathrm{~km}$ and $2.5 \mathrm{~km}$ below $50 \mathrm{~km}$.

\section{Comparison of measurement and modelling results}

In this section measurement data for the two selected days (14 and 17 September 2003) are compared to the radiative transfer simulations. This comparison covers various aspects: first, it should confirm the applied concept as well as both radiative transfer simulations and measurements. Second, it should provide an overview of the general range of variability of the different quantities, especially depending on the aerosol optical depth. Third, it should show how the results depend on the viewing geometry (especially the elevation angles and relative azimuth angles).

The aerosol load on both selected days is systematically different. From AERONET observations at Ispra it is found that on 14 September 2003 the aerosol optical depth was low (0.1-0.2), and on 17 September 2003 rather high (0.6-0.9), see Fig. 2. For both days, also substantial variations over the course of the day are found. For comparison with the MAXDOAS observations (see below) it should be taken into account that the distance between Ispra and the Milan is rather large (about $60 \mathrm{~km}$ ), and also the local conditions are quite different: Ispra is already located within the Alps, while Milan is located in the Po valley. Thus the aerosol optical depth at Ispra can be only used for a rough comparison with the MAX-DOAS observations.

From the comparison of the MAX-DOAS observations with the radiative transfer simulations (for details see below), it is found, that the values for the aerosol optical depth of about 0.1 and 1.0 lead to best agreement for the two selected days (see Figs. 3 and 4). This finding matches well with the AERONET observations.

In the model simulations the aerosol extinction was assumed to be constant between the surface and $1 \mathrm{~km}$; for the single scattering albedo and the asymmetry parameter 1.0 and 0.68 were assumed, respectively. The surface albedo was set to $5 \%$ and the solar zenith and relative azimuth angles were set to the respective values for the three viewing angles during the day (see Fig. 1). The results for both days in between (15 and 16 September 2003, see Wagner et al., 2004) were not compared to model simulations in detail, since they were partly affected by the presence of clouds; the aerosol load on these days ranged between the values of 14 and 17 September 2003. 

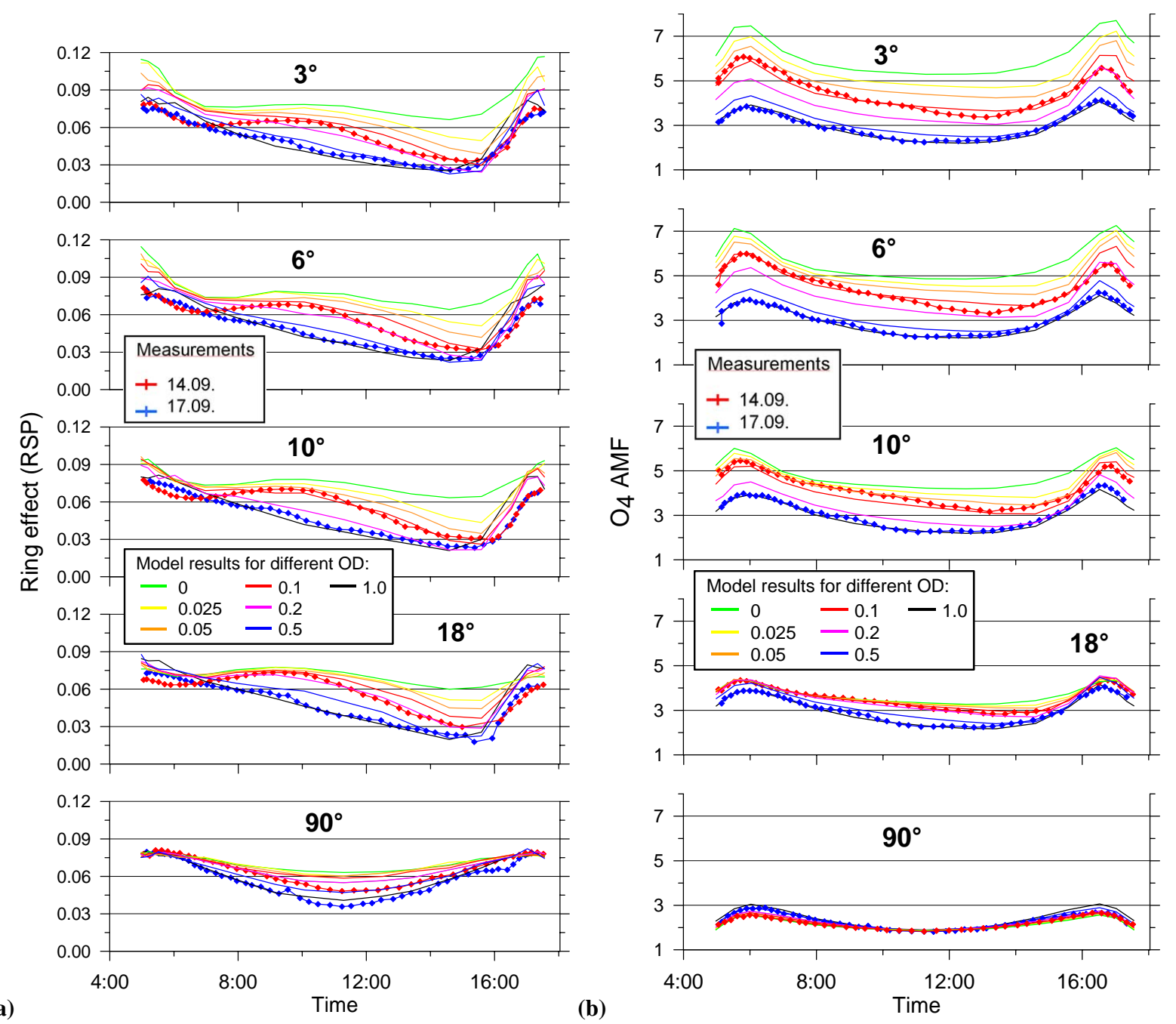

Fig. 4. Comparison between measurements of the western telescope (red: 14. September; blue: 17 September) and model results for various optical depths. The comparison is performed for individual elevation angles (top: $3^{\circ}$ to bottom $90^{\circ}$ or $18^{\circ}$ ). Besides the Ring effect (a) also the $\mathrm{O}_{4} \mathrm{AMF}(\mathbf{b})$, the radiance (c), and the radiance ratio (d) are shown.

Figure 3 shows the comparison of the 4 measured quantities (RSP, $\mathrm{O}_{4} \mathrm{AMF}$, radiance and radiance ratio) for the two selected days with the modelled quantities for the western telescope; the thin lines show the model results for different optical depth (for the measured $\mathrm{O}_{4} \mathrm{AMF}$ and the RSP the respective values of the Fraunhofer reference spectrum are added, see Sect. 2). The measured radiance was scaled by a multiplicative factor until the best overall match was achieved. Thus this comparison should be treated with caution.

In general, rather good agreement is found between measurements and model results. For most results, not only the diurnal variation shows the same qualitative behaviour, but also the absolute values agree. It is interesting to note that for both the measured and modelled radiances the dependence on the elevation angle changes in a similar way between 14 and 17 September 2003.
Discrepancies between measurements and model results are mainly found for the RSP (especially at large SZA) and for the radiance and radiance ratio. The differences for the latter two quantities are most probably caused by the suspected presence of very thin clouds (see Sect. 5.2) and spatial and temporal variations of the aerosol load. From AERONET data at Ispra it is found that the aerosol optical depth varied significantly during the two selected days (see Fig. 2). Also differences of the assumed single scattering albedo and asymmetry parameter might be responsible for part of the discrepancies. The deviations of the Raman scattering probability at large SZA are probably related to the presence of stratospheric aerosols (see Sect. 5.2).

Like for the $\mathrm{O}_{4}$ AMF, the Raman scattering probability decreases in general with increasing aerosol optical depth, because of the decreased light path along the line of sight. However, compared to the $\mathrm{O}_{4} \mathrm{AMF}$, the Raman scattering 

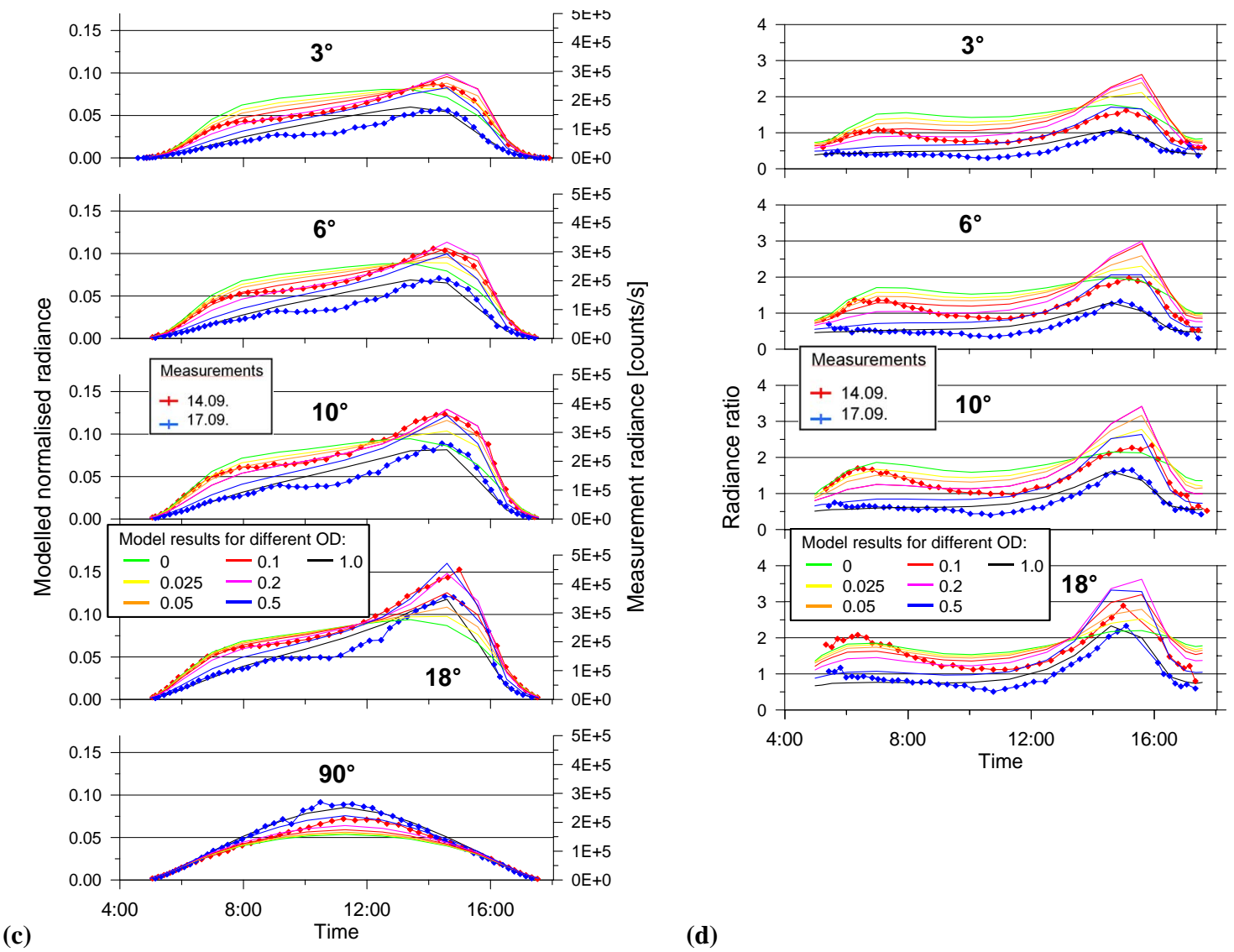

(c)

Fig. 4. Continued.

probability depends much more strongly on the relative azimuth angle.

For the radiance, increasing aerosol load can either increase or decrease the values for different elevation angles. In general, the radiance tends to increase for zenith view, but tends to decrease for lower elevation angles (see also discussion in Wagner et al., 2004). The radiance depends also on the relative azimuth angle. A strong increase of the radiance is found around 15:00, when the relative azimuth angle approaches zero. This indicates the strong probability of aerosol scattering in the forward direction.

The radiance ratio is in general decreased for increasing aerosol load. This is caused by the combined effects of decreased radiances for low elevation angles and increased radiance for zenith view. The increased radiance for zenith view is caused by the additional photons scattered by the aerosol particles. For low elevation angles, the situation is more complex: even in the absence of aerosols the optical depth along the line of sight is typically much larger than unity. Thus, additional aerosols do basically not enhance the overall probability for solar photons to be scattered into the instrument. The decrease of the observed radiance is instead mainly caused by the increased probability for multiple scattering including multiple reflections at the low surface albedo.

Note that for the other two azimuth angles very similar results were found, but the effect of the relative azimuth angle is smaller (see Appendix).

A more detailed comparison between measurements and model results for the individual elevation angles is presented in Fig. 4. Again the observations of the western telescope are selected, because it shows the strongest effects of the relative azimuth angle. The other viewing directions show similar results.

The red and blue lines with dots show the results of the measurements for both selected days. The lines without dots represent model results for different aerosol optical depths ranging from zero (blue line, Rayleigh atmosphere) to unity (black line). The comparison shown in Fig. 4 leads to the same overall conclusions as those shown in Fig. 3. In general, the best agreement is found for the $\mathrm{O}_{4}$ AMF. The observed differences for the radiance, the radiance ratio, and the Raman scattering probability can be most probably related to the simplified assumptions on the aerosol properties and on the effect of stratospheric aerosols (see Sect. 5.2). 


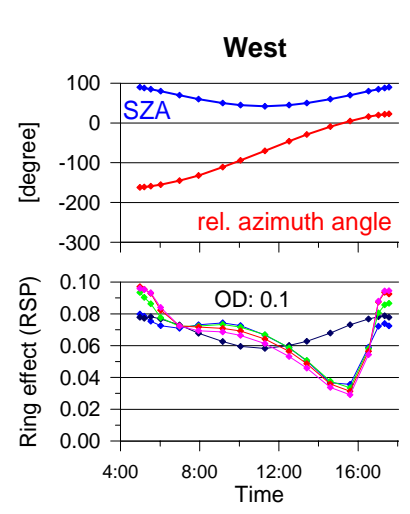

(a)

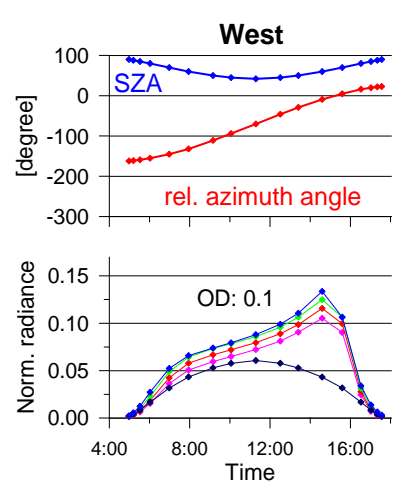

(c)

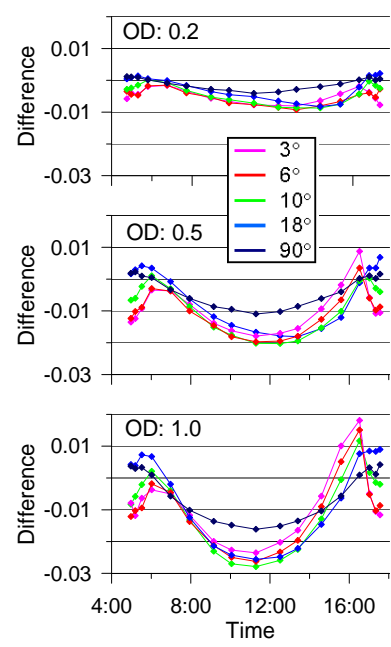

(b)

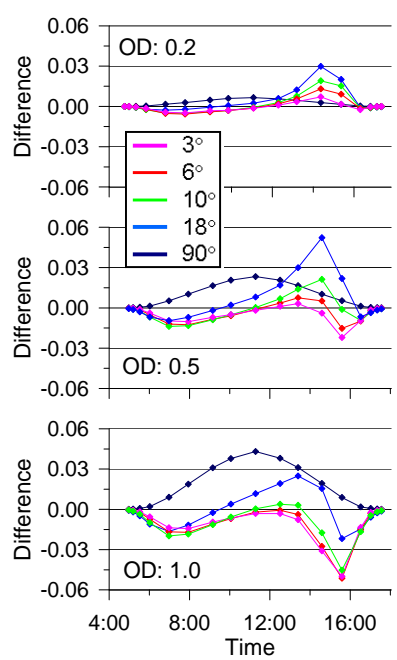

(d)
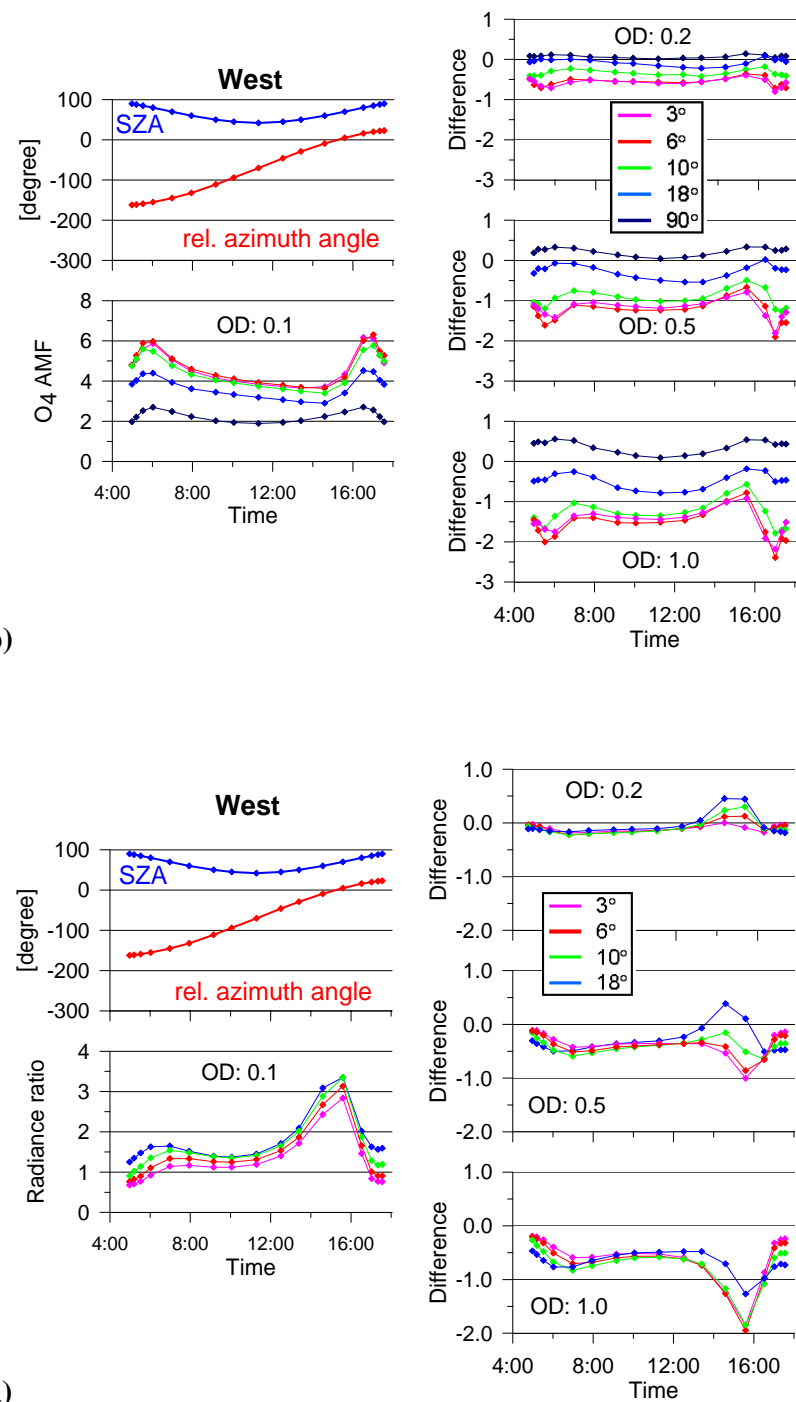

Fig. 5. Modelled dependencies of the diurnal profiles of the following quantities: Ring effect (a), $\mathrm{O}_{4}$ AMF (b), radiance (c) and radiance ratio (d) on the optical depth of the aerosol (constant extinction 0-1 km, single scattering albedo: 1.0, AP: 0.68). In the left two diagrams of each set (a-d) the SZA and relative azimuth angle (top) and the simulations for an aerosol OD of 0.1 (bottom) are shown. In the right column the differences of the above quantities for different aerosol ODs $(0.2,0.5,1.0)$ compared to those for OD=0.1 are shown. Results for the western telescope.

\section{Sensitivity studies}

\subsection{Dependence of the observed quantities on aerosol properties and surface albedo}

In this section, the dependencies of the 4 selected quantities on various aerosol properties are investigated. One specific aim is to identify situations, for which the observation of the Ring effect can provide additional information to those retrieved from observations of $\mathrm{O}_{4}$ and the radiance. In addition to the effects of aerosols, also the effects of surface albedo, high clouds and stratospheric aerosols are considered. Again, to minimise the number of graphs, the results are restricted to one viewing direction. Because of the strong influence of the relative azimuth angle, the western telescope was selected.

In Fig. 5 the dependence of the simulated quantities (RSP, $\mathrm{O}_{4}$ AMF, radiance and radiance ratio) on the aerosol optical depth is shown. On the left hand side of each panel, the details on the viewing geometry as well as the results for a standard scenario are shown. The aerosol properties of the standard scenario were chosen like above (constant extinction $0-1 \mathrm{~km}$, single scattering albedo: 1.0, AP: 0.68), but with an aerosol optical depth of 0.1 . At the right hand side of each panel the deviations of the results for different optical depths from those of the standard scenario are shown. 
(a) Ring effect (RSP)

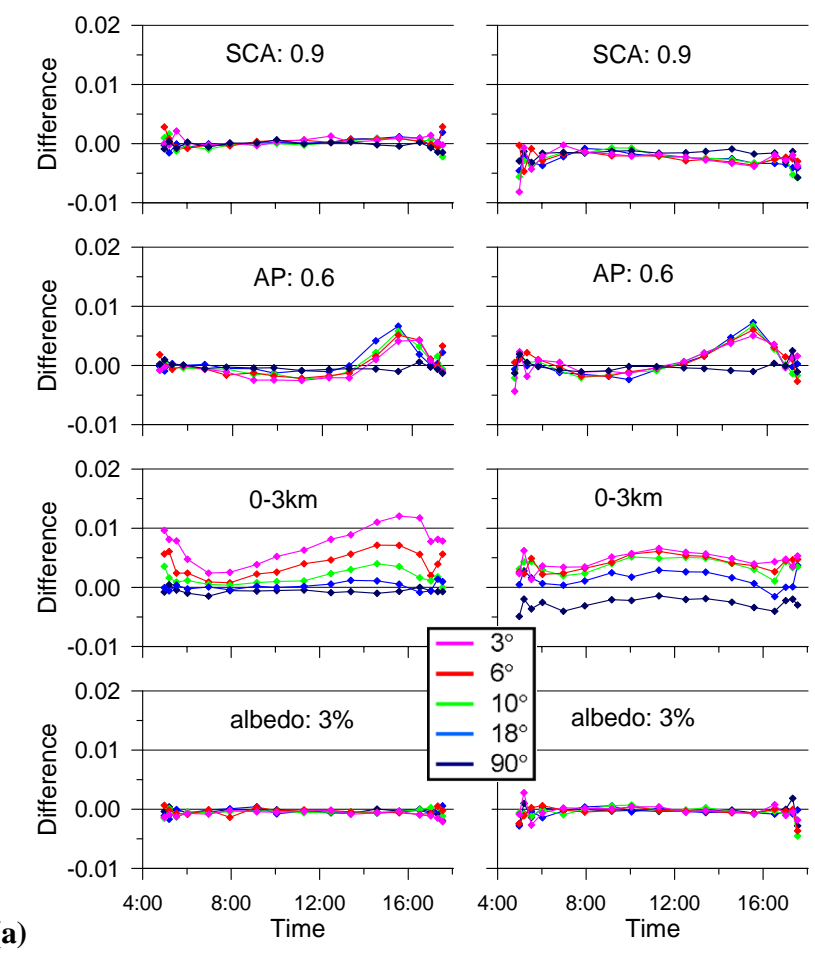

(b) $\mathrm{O}_{4} \mathrm{AMF}$
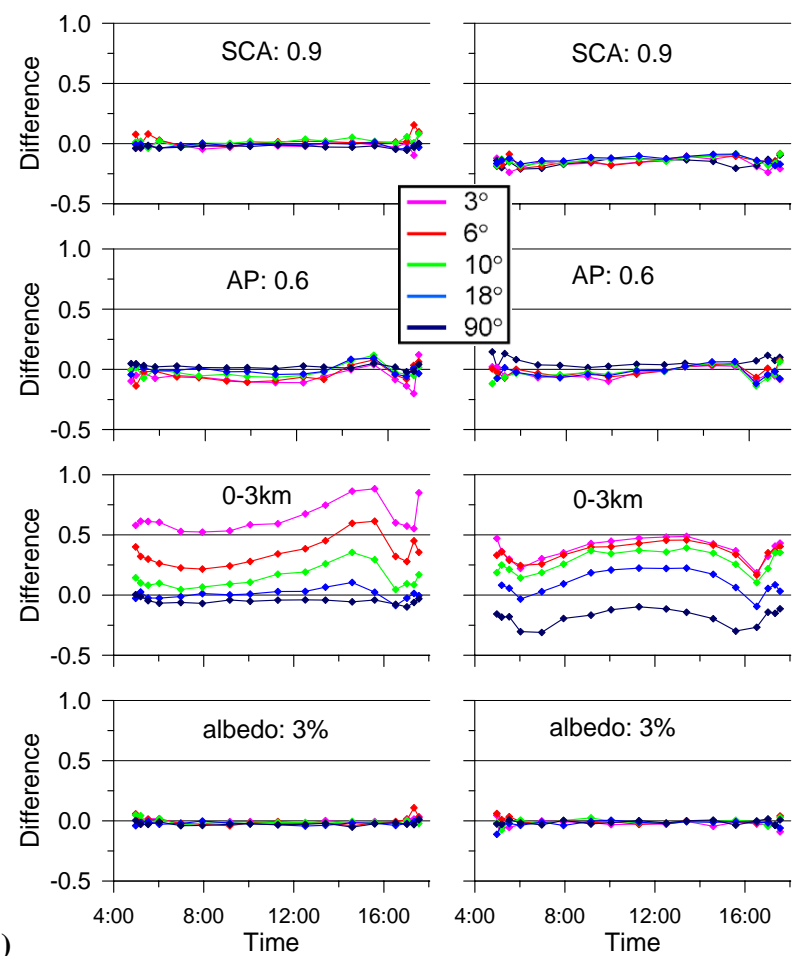

Fig. 6. Influence of various aerosol properties and the surface albedo. The different panels show (a) the strength of the Ring effect, (b) $\mathrm{O}_{4}$ AMF, (c) radiance, (d) radiance ratio (left: OD: 0.1; right: OD: 1.0). The results are expressed as differences compared to the case with constant extinction between $0-1 \mathrm{~km}$, single scattering albedo: 1.0, AP: 0.68 , and surface albedo: $5 \%$. Only one parameter is changed (as indicated in the figures). Results for the western telescope.

For both $\mathrm{O}_{4}$ AMF and RSP, a strong dependence on the aerosol optical depth is found, especially for observations at low elevation angle. For the radiance and radiance ratio, depending on the viewing angles and solar zenith angle, an increase or decrease is found.

In Fig. 6, the influence of several other aerosol properties on the selected quantities is shown. Here, only the differences with respect to the standard scenarios (constant extinction 0-1 km, single scattering albedo: 1.0, AP: 0.68) for an optical depth of 0.1 (left hand side) or 1.0 (right hand side) are presented. In addition to the aerosol properties, also the effects of changes of the surface albedo are included.

For the RSP, the strongest effects are found for changes of the layer height. Especially for low optical depth, the RSP increases with increasing layer height. This is most probably caused by the fact that the absorption path along the line of sight is increased if the aerosol load is distributed over a larger height interval. Accordingly, the probability of molecular scattering increases. Also the asymmetry parameter can have a strong effect on the RSP, but only for conditions with rather small relative azimuth angle. Under such conditions, a decrease of the asymmetry parameter leads to an increase of the Raman scattering probability, because more photons are scattered from the side into the line of sight. Such photons have a larger probability to be scattered by molecules.

For the $\mathrm{O}_{4} \mathrm{AMF}$ also the height of the aerosol layer has a substantial effect. With increasing height of the aerosol layer the absorption paths along the line of sight become longer and accordingly the $\mathrm{O}_{4}$ absorption is increased. In contrast to the RSP, for the $\mathrm{O}_{4}$ AMF the influence of the asymmetry parameter is rather small indicating the fact that the absorption path for photons which were scattered from the side into the line of sight are rather similar to those scattered in the forward direction. For the radiance and the radiance ratio, the influence of the single scattering albedo (especially for large optical depth) becomes important. Also the other parameters (except the surface albedo) can have a considerable effect, but only for relative azimuth angles close to zero.

\subsection{Dependence of the observed quantities on the pres- ence of high cirrus and stratospheric aerosols}

In addition to the influence of near-surface aerosols the observed quantities can be also strongly affected by clouds. Clouds shield the incoming direct solar light, and multiple scattering events inside extended clouds can lead to strongly 
(c) Radiance

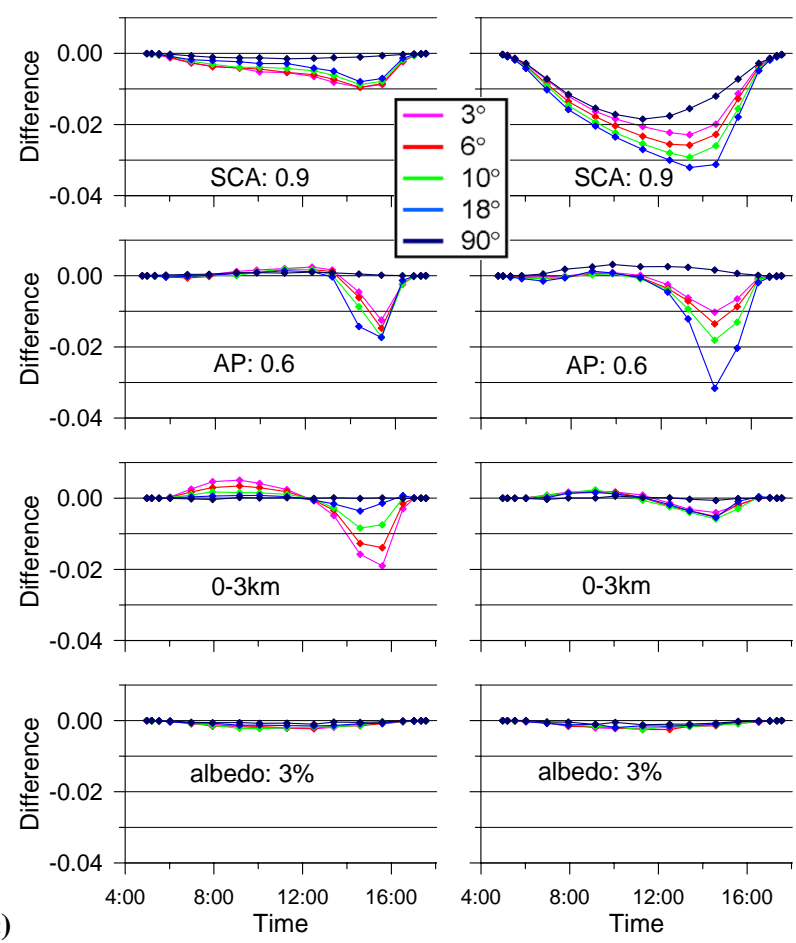

(d) Radiance ratio

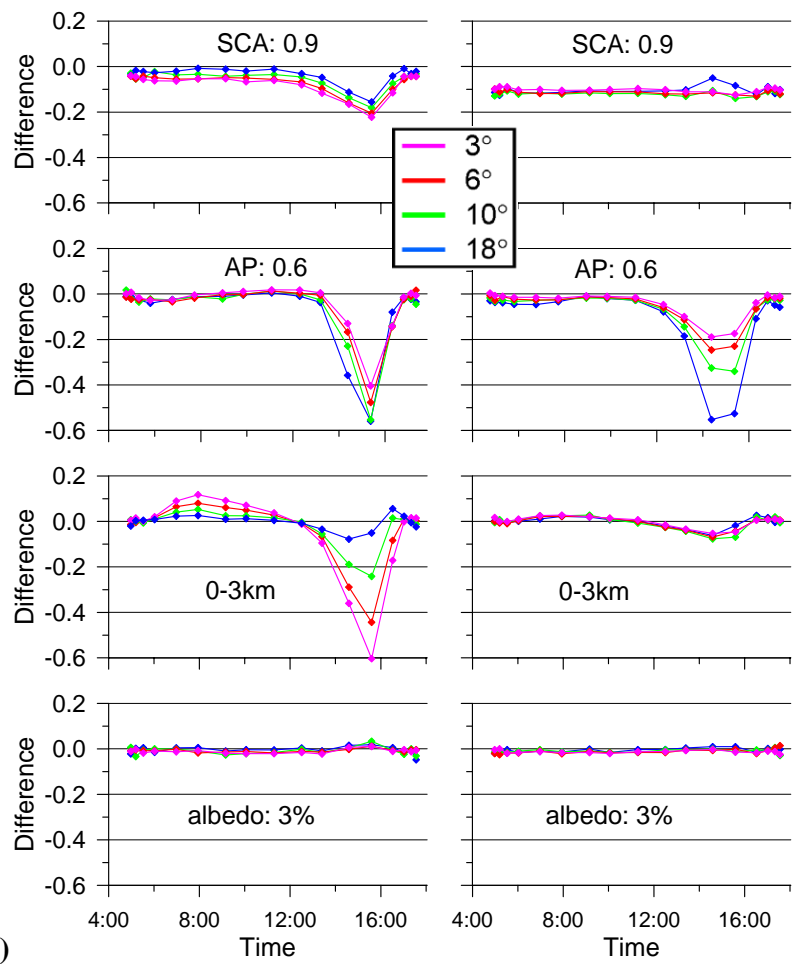

Fig. 6. Continued.

enhanced atmospheric absorption paths (Erle et al., 1995; Wagner et al., 1998; Pfeilsticker et al., 1998; Wagner et al., 2004). In the presence of extended and optically thick clouds, the determination of aerosol properties using MAX-DOAS observations might become impossible or is at least strongly limited.

The presence of clouds can be usually detected by the observed quantities themselves, in particular by strong deviations of the observed radiance, $\mathrm{O}_{4}$ AMF and RSP from the respective values for clear sky. Often also the rapid temporal variation of the observed quantities (caused by changes in the cloud properties) are a clear indication for the cloud presence.

However, in some cases, the presence of thin (possibly sub-visible) clouds might not be obvious from the observed quantities. Such cases are investigated in this section. In Fig. 7 the effects of a thin homogenous cirrus clouds (optical depth either 0.2 or 1.0) between 9 and $10 \mathrm{~km}$ are shown, expressed as differences compared to the standard aerosol scenario with optical depth 0.1 , constant extinction $0-1 \mathrm{~km}$, single scattering albedo: 1.0 , and AP: 0.68 . The results indicate that for clouds with an optical depth of about unity or larger, it should be possible to discriminate the effects from those of aerosols close to the surface (by inspecting the par- ticular diurnal variations of the observed quantities). However, for cirrus clouds with very small optical depths, this will be a very challenging task, in particular if the aerosol or cloud properties also change during the day. In general, the possible presence of thin cirrus clouds constitutes a fundamental error source for the retrieval of aerosol properties from MAX-DOAS observations (also for other observations like sun photometers). In particular, observations of the Ring effect (and the $\mathrm{O}_{4}$ absorption) in zenith direction can be offset by the presence of thin cirrus clouds. One promising way to discriminate the effects of thin clouds from those of aerosols could be to study the wavelength dependence: while the wavelength dependence of scattering by cloud particles is weak (i.e., clouds are white), that of aerosol scattering shows a strong wavelength dependence. Thus the relation of the strength of the Ring effect at different wavelengths should be different for clouds and aerosols.

In addition, also stratospheric aerosols can affect the observed quantities. Especially during sunset and sunrise, the first scattering events of the incoming sun light usually take place at high altitudes, where stratospheric aerosols could alter the atmospheric scattering properties.

During the period when the MAX-DOAS observations were carried out, the stratospheric aerosol load was rather 

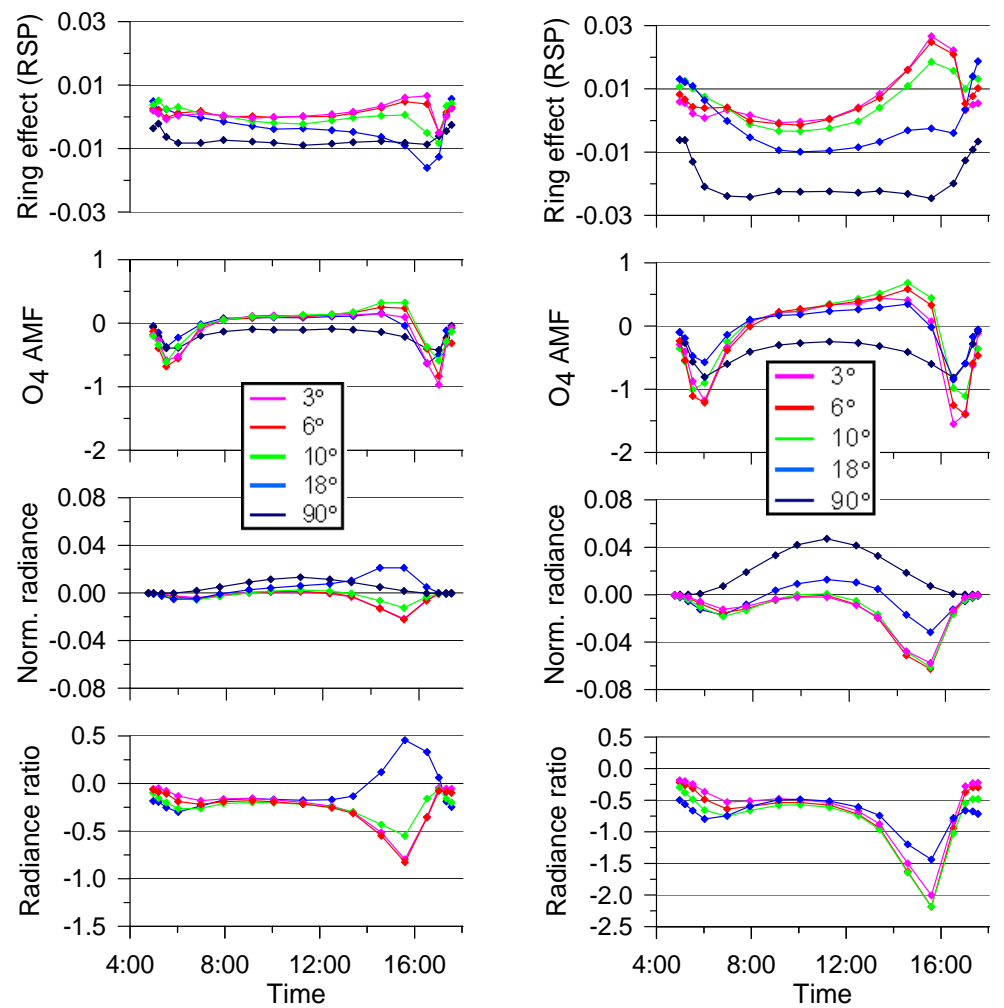

Fig. 7. Influence of high cirrus clouds on the measured quantities. The aerosol properties are constant extinction 0-1 km, OD: 0.1, single scattering albedo: 1.0, AP: 0.68. The cirrus clouds have optical depths of 0.2 (left) and 1.0 (right) and are located between 9 and $10 \mathrm{~km}$ (AP: 0.68 , single scattering albedo: 1 ).

small, since for a long time no strong volcanic eruption had taken place (see e.g. http://data.giss.nasa.gov/modelforce/ strataer/). From the SAGE-II satellite instrument, the total stratospheric aerosol optical depth at $1020 \mathrm{~nm}$ was found to be below 0.002 (see e.g. http://data.giss.nasa.gov/sageii/). However, because the stratospheric aerosol particles are small, the optical depth at $360 \mathrm{~nm}$ is expected to be substantially larger. In Fig. 8 the influence of two assumed stratospheric aerosol profiles on the observed 4 quantities is shown. Both assumed stratospheric profiles extend from $15-25 \mathrm{~km}$ with constant extinction with a total optical depth of either 0.01 or 0.02 . The single scattering albedo and the asymmetry parameter are assumed to be 1.0 and 0.68 , respectively. Again, the results are expressed as differences to the standard aerosol scenario for an optical depth of 0.1 (constant extinction $0-1 \mathrm{~km}$, single scattering albedo: 1.0 , AP: 0.68). The assumed stratospheric aerosol optical depth is rather small compared to those used near the surface. Nevertheless, for large SZA, systematic differences compared to the standard scenario are found (except for the radiance). Especially for the RSP, the presence of stratospheric aerosols can then lead to a systematic decrease. This effect is probably the main reason for the deviation between measurement results and model simulations as seen in Fig. 4. Other reasons might include the effects of polarisation and refraction, which are both not included in the current version of our model.

Because of their high sensitivity, Ring effect observations at large SZA might become a well suited tool to retrieve the stratospheric aerosol optical depth, especially during periods of very low stratospheric aerosol loads. Of course, besides the effects of stratospheric aerosols, also tropospheric aerosols will influence the Ring effect during twilight (see e.g. Fig. 5a). However, compared to the influence at smaller SZA, their influence at SZA around $90^{\circ}$ is much smaller. Thus, it might be possible to correct the observations at twilight for the influence of tropospheric aerosols using the aerosol parameters determined at lower SZA (for which the effect of stratospheric aerosols is negligible). Another (and probably more important) way to separate the impact of tropospheric aerosols (and clouds) from the observed Ring effect during twilight might be the detailed investigation of the temporal variability. While troposopheric aerosols are usually subject to a high temporal variability, stratospheric aerosols change on much longer time scales. Thus it should at least be possible to estimate an upper limit for the stratospheric aerosol optical depth. Future studies are needed to explore in detail the possibilities of Ring effect observations to determine the stratospheric aerosol optical depth. 

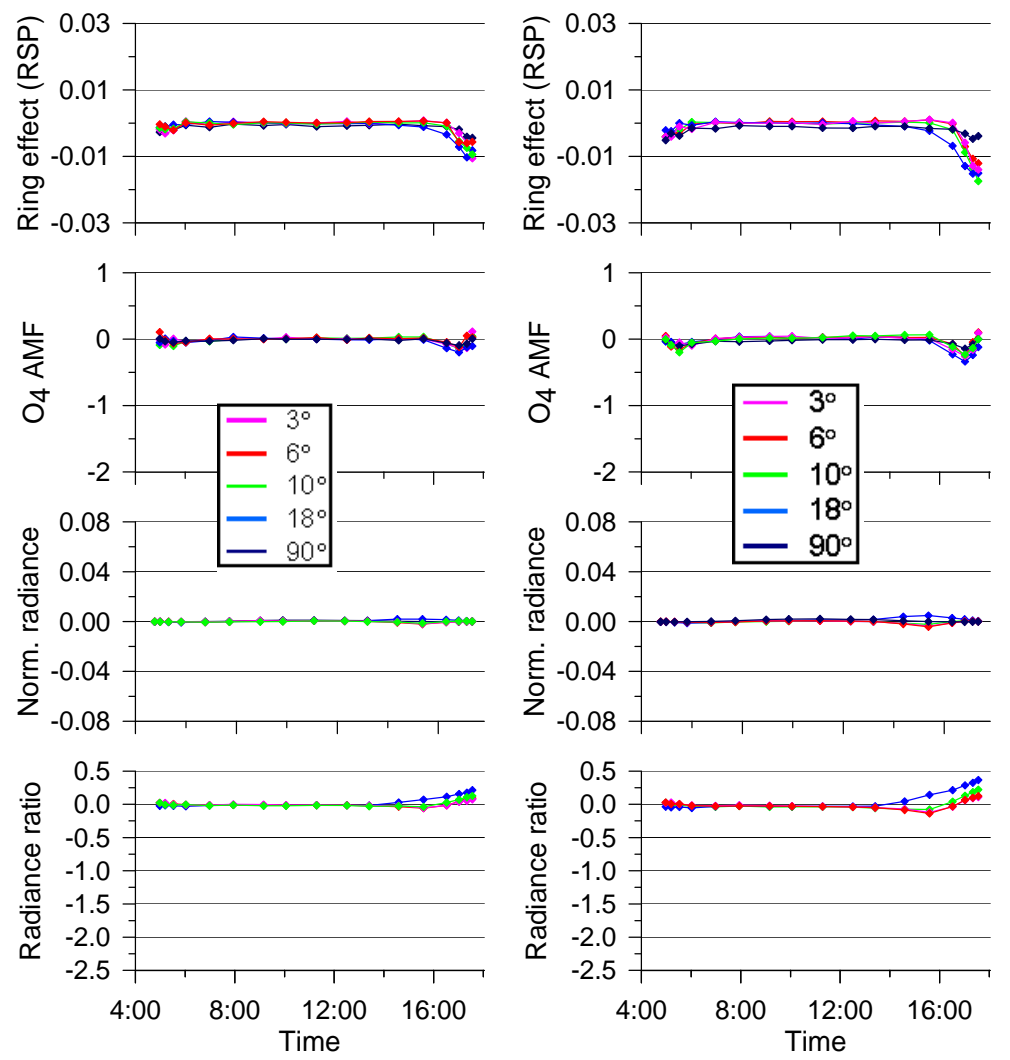

Fig. 8. Influence of two different stratospheric aerosols properties on the measured quantities. The aerosol properties are constant extinction 0-1 km, OD: 0.1, single scattering albedo: 1.0, AP: 0.68 . The stratospheric aerosol has optical depths of 0.01 (left) and 0.02 (right) with constant extinction between 15 and $25 \mathrm{~km}$ (AP: 0.68, single scattering albedo: 1 ).

\subsection{Special cases with strong potential of Ring effect ob- servations for the retrieval of aerosol properties}

In many situations, the influence of aerosols on the RSP and the $\mathrm{O}_{4}$ AMF shows a very similar qualitative dependence. This can be understood from the fact that an increase (decrease) of the atmospheric light path will in general lead to an increased (decreased) $\mathrm{O}_{4}$ absorption as well as to an increased (decreased) probability for molecular scattering. Nevertheless, there are also interesting differences in the detailed dependencies, some of them will be discussed in this section.

Figure 9 shows the diurnal variation of the measured and modelled RSP and the $\mathrm{O}_{4} \mathrm{AMF}$ for the 18 degree elevation of the western telescope (same data as shown in Fig. 4). For different times of the day the modelled Raman scattering probabilities for different aerosol optical depth indicate a quite different sensitivity either to small or large aerosol optical depths. Around 11:00, the curves for low aerosol optical depth show only little differences, while those for aerosol optical depths $>0.2$ show large differences, indicating a high sensitivity for optical depths $>0.2$. In contrast, around 15:00 the modelled curves for small aerosol optical depths $(<0.2)$ show large differences, while those for larger optical depths show only small differences, indicating a high sensitivity for optical depths $<0.2$. A similar behaviour is also found for the $\mathrm{O}_{4}$ AMFs (Fig. 9b), but with rather small absolute differences. Thus observations of the Ring effect might be especially well suited for an optimisation of the sensitivity for situations with different aerosol optical depths.

Another interesting application for Ring effect observations is found for observations in zenith viewing direction. In Fig. 10 the diurnal variation of the measured and modelled RSP and $\mathrm{O}_{4}$ AMF for the 90 degree elevation (same data as shown in Fig. 4). Except for large SZA, the RSP depends strongly on the aerosol optical depth. In contrast, the $\mathrm{O}_{4}$ AMF shows only a weak dependence. Here it is also interesting to note that the aerosol profile has only a small effect on the RSP measured in zenith direction: at low solar zenith angles, the influence of a change of the profile height from $1 \mathrm{~km}$ to $3 \mathrm{~km}$ is about $10 \%$ of the change of the aerosol optical depth from 0 to 1 (see also Fig. 6a). This effect decreases further towards larger wavelengths (e.g. $<5 \%$ at $500 \mathrm{~nm}$ ), because of the decreasing probability for scattering by molecules.

These findings indicate the large potential of zenith viewing DOAS instruments for the determination of aerosol 


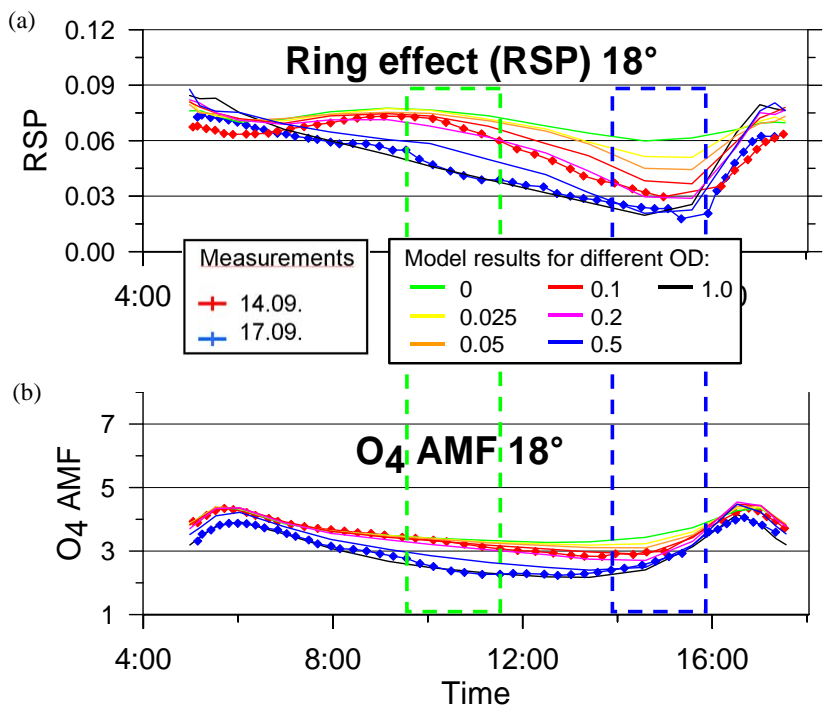

Fig. 9. Diurnal variation of the measured and modelled values of the Raman scattering probability (a) and the $\mathrm{O}_{4}$ AMF (b) for the western telescope at $18^{\circ}$ elevation (same data as in Fig. 4). Depending on the viewing geometry the Ring effect observations are especially sensitive for low OD (green rectangle) or high OD (blue rectangle).

properties. From the analysis of the Ring effect, information on aerosol properties could thus be derived from many UV instruments prior to the MAX-DOAS era.

Finally, as shown in the previous sub-section, observations of the Ring effect at large SZA might provide information on stratospheric aerosol properties, even for very small optical depths $(<0.01)$.

All three examples indicate potential areas in which the analysis of the Ring effect might provide valuable information in addition to the analysis of the $\mathrm{O}_{4}$ absorption. Additional possibilities might be discovered from further sensitivity studies, especially including other wavelengths.

\section{Conclusions}

In this study the first quantitative comparison of MAXDOAS observations of the Ring effect with model simulations is presented. The comparison is performed for two cloud-free days with different atmospheric aerosol loads. It also includes a large variety of viewing geometries: SZA between about $45^{\circ}$ to $90^{\circ}$, elevation angles at $3^{\circ}, 6^{\circ}, 10^{\circ}$, $18^{\circ}$ and $90^{\circ}$ (zenith), as well as three azimuth angles (North, West, South). The variety of atmospheric conditions and viewing geometries allowed a comprehensive test of our capabilities to measure and model the Ring effect. In addition to the Ring effect, also the observed $\mathrm{O}_{4}$ absorptions and radiances are compared to the model simulations. In general good agreement was found. Discrepancies occurred mainly for the radiance and the Ring effect at large SZA. The differ-

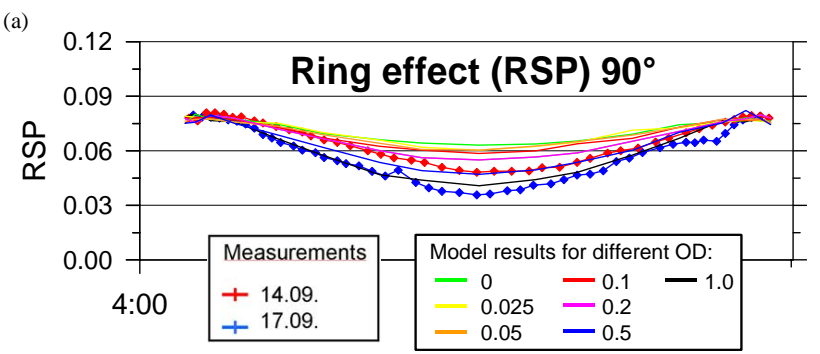

(b)

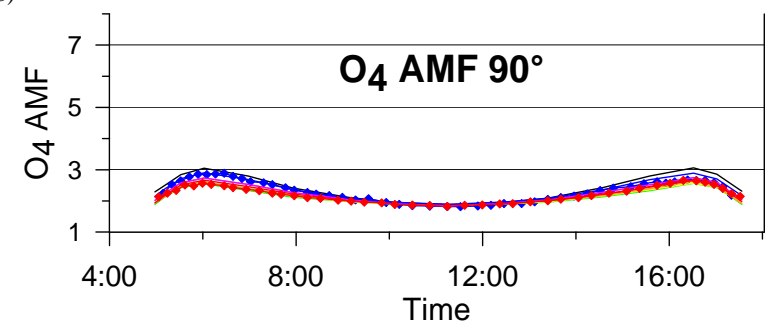

Fig. 10. Diurnal variation of the measured and modelled values of the Raman scattering probability (a) and the $\mathrm{O}_{4}$ AMF (b) for the telescopes at $90^{\circ}$ elevation (same data as in Fig. 4). For Zenith observations the analysis of the Ring effect can provide more information on aerosol properties than the $\mathrm{O}_{4}$ absorption, especially during noon.

ences in the radiance are most probably caused by the simplified assumptions of the aerosol scenarios (especially with respect to the values of the asymmetry parameter and the single scattering albedo). Also thin cirrus clouds and horizontal gradients of the aerosol properties might explain part of the differences. The differences of modelled and measured Ring effect at large SZA might be related to several reasons: first, for such viewing geometries, the effects of polarisation and refraction might become important. Both effects are currently not included in our radiative transfer model. In addition, it was found that at large SZA, even very small stratospheric aerosol loads can have a relatively strong effect on the Ring effect.

Several sensitivity studies were carried out to investigate the influence of different aerosol properties on the Ring effect (and the $\mathrm{O}_{4}$ absorption and radiance). It was found that for most measurement situations, the aerosol optical depth has by far the strongest influence on the observed quantities. However, several other parameters can also have a substantial influence on the quantities derived from MAX-DOAS observations. Here it is interesting to note that the different quantities show specific sensitivities to different aerosol parameters and should be used in a complementary way in future applications. The $\mathrm{O}_{4}$ absorption is mainly sensitive to the atmospheric light path distribution and is thus most sensitive to the aerosol optical depth and height profile. The Ring effect is also sensitive to the atmospheric light path distribution, but in addition it depends systematically on the properties of the scattering processes. Especially for small relative 
azimuth angles, Ring effect observations are thus sensitive to the aerosol phase function. The observed radiance is most sensitive to properties of the scattering processes, but is almost independent of the atmospheric light path distribution. In contrast to observations of the $\mathrm{O}_{4}$ absorption and the Ring effect, the radiance depends strongly on the aerosol absorbing properties (see also Frieß et al., 2006).

Observations of the Ring effect might become especially interesting for two specific applications: Ring effect observations at large SZA could allow to retrieve stratospheric aerosol properties, even in cases with very low stratospheric aerosol optical depths. While this might become an interesting tool to monitor the temporal evolution of stratospheric aerosols, more research is needed to explore the full potential of Ring observations.

In addition, for conventional zenith scattered light observations, the analysis of the Ring effect provides a unique opportunity to retrieve aerosol properties, since in contrast to the $\mathrm{O}_{4}$ absorption the Ring effect depends strongly on the aerosol optical depth. It should be also noted here, that such retrievals are rather straightforward, because no dependence on the relative azimuth angle has to be considered. Also the (relative) aerosol profile has a rather small effect on the observation of zenith scattered light. The analysis of the Ring effect might thus allow to create long term data sets of aerosol properties from existing zenith UV observations prior the MAX-DOAS era.
Future studies should investigate the aerosol influence on the Ring effect at additional wavelengths. This might become a very important aspect, because in contrast to $\mathrm{O}_{4}$ absorptions, the Ring effect can be retrieved almost continuously over large wavelength intervals. Also radiative transfer simulations should be improved by including the effects of polarisation and refraction. Finally, inversion techniques based on least squares algorithms or optimal estimation should be developed taking into account the observed radiances, the Ring effect and $\mathrm{O}_{4}$ absorptions.

As a side product of our studies, we derived information on the $\mathrm{O}_{4}$ absorption cross section for $360 \mathrm{~nm}$ at atmospheric conditions. The retrieved value of $5.27 \times 10^{46} \mathrm{~cm}^{5} / \mathrm{molec}^{2}$ is about $25 \%$ larger than the values obtained in the laboratory from Greenblatt et al. (1990) and Hermans (http: //www.aeronomie.be/spectrolab/o2.htm). One possible reason might be the temperature dependence of the $\mathrm{O}_{4}$ cross section, since the effective atmospheric temperature during the measurements was colder $(267 \mathrm{~K})$ than those of the laboratory measurements at room temperature. The value of the $\mathrm{O}_{4}$ cross section at $360 \mathrm{~nm}$ found from this comparison is close to the values found by Volkamer (1996) $\left(5.42 \times 10^{46} \mathrm{~cm}^{5} / \mathrm{molec}^{2}\right)$ and Perner and Platt (1980) $\left(5.4 \times 10^{46} \mathrm{~cm}^{5} / \mathrm{molec}^{2}\right)$. 


\section{Appendix A}

Comparison of measurements and model simulations for the northern and southern telescope

\section{Ring effect, northern telescope}
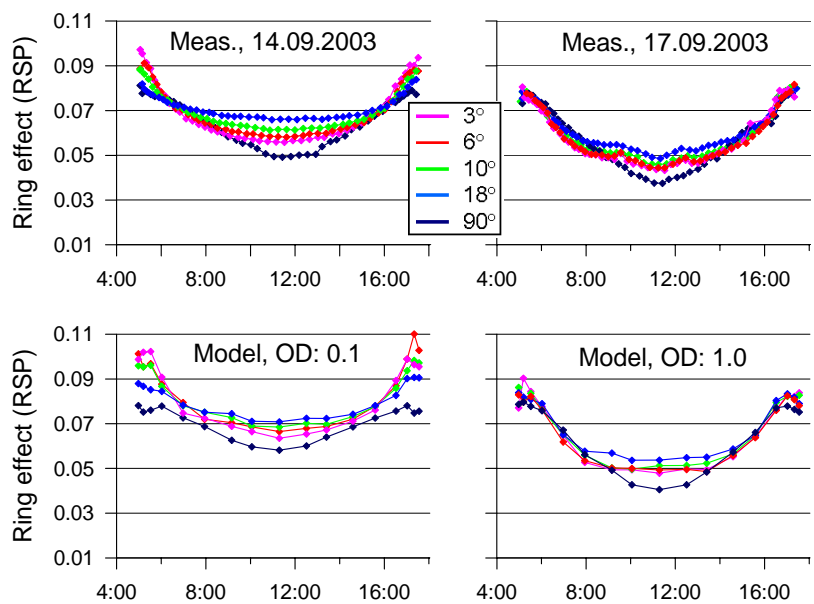

$\mathrm{O}_{4}$ absorption, northern telescope
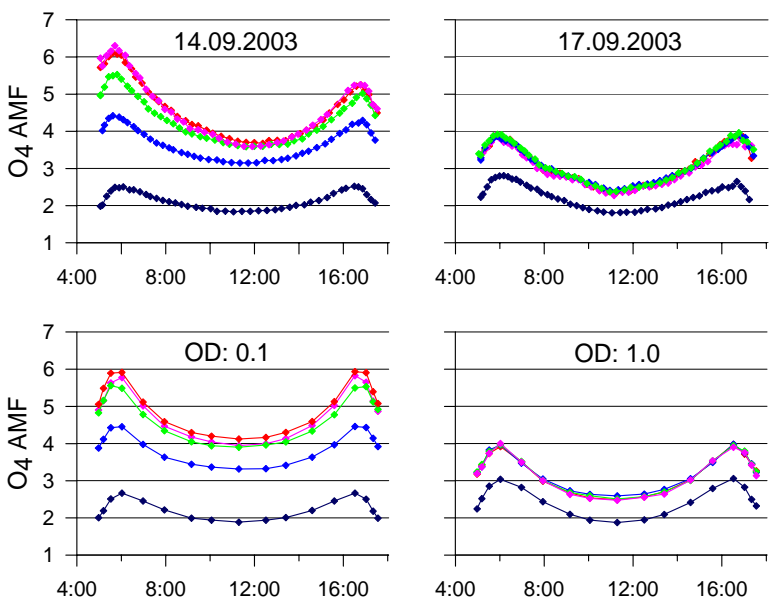

Fig. A1. Same as Fig. 3, but for the northern and southern telescopes: Comparison of measurements and model results for the western telescope on two selected days (14 and 17 September 2003). Besides the Ring effect, also the $\mathrm{O}_{4}$ AMF and the measured radiance and radiance ratio are displayed. In each sub-plot the upper graphs show the measurement results for the 14 September (left) and 17 September (right); the lower graphs show model results for aerosol OD of 0.1 (left) and 1.0 (right). Further aerosol properties are: constant extinction between 0 and $1 \mathrm{~km}$, single scattering albedo of 0.9 , asymmetry parameter of 0.68 .

\section{Radiance, northern telescope}
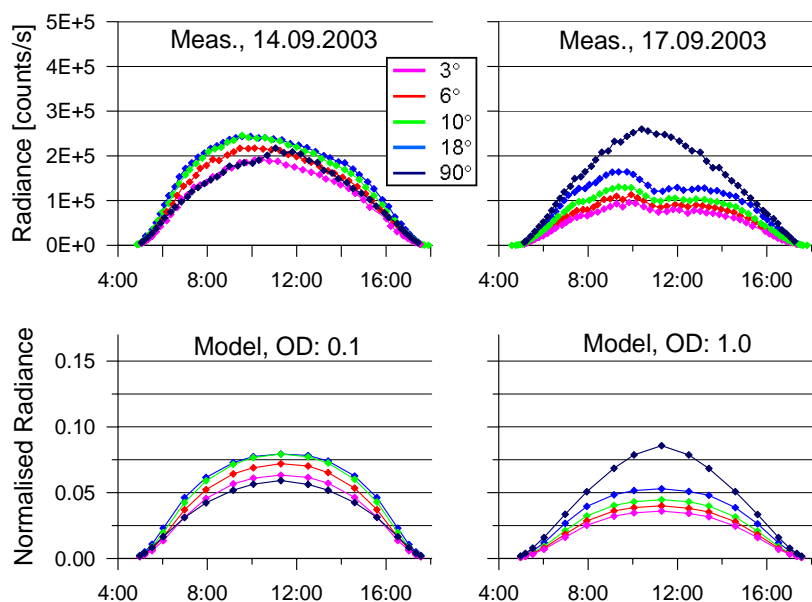

Radiance ratio, northern telescope
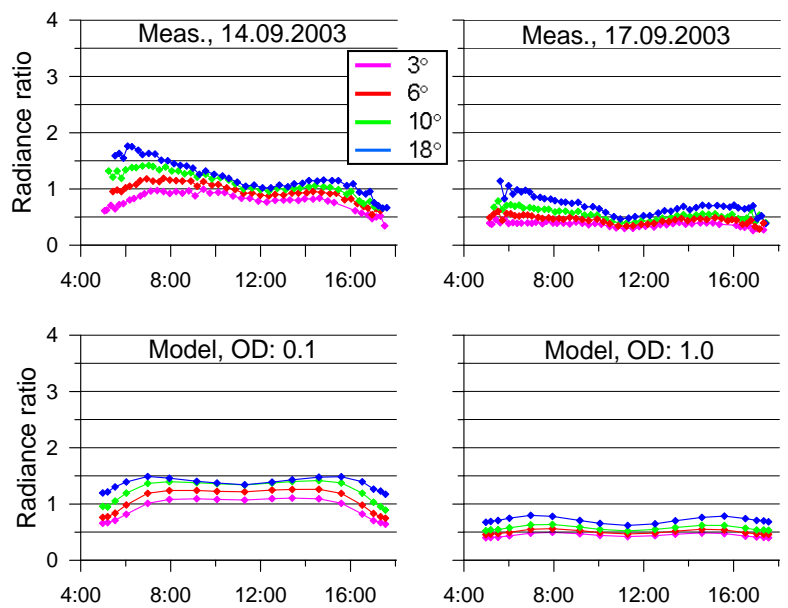

Fig. A1. Continued. 


\section{Ring effect, southern telescope}
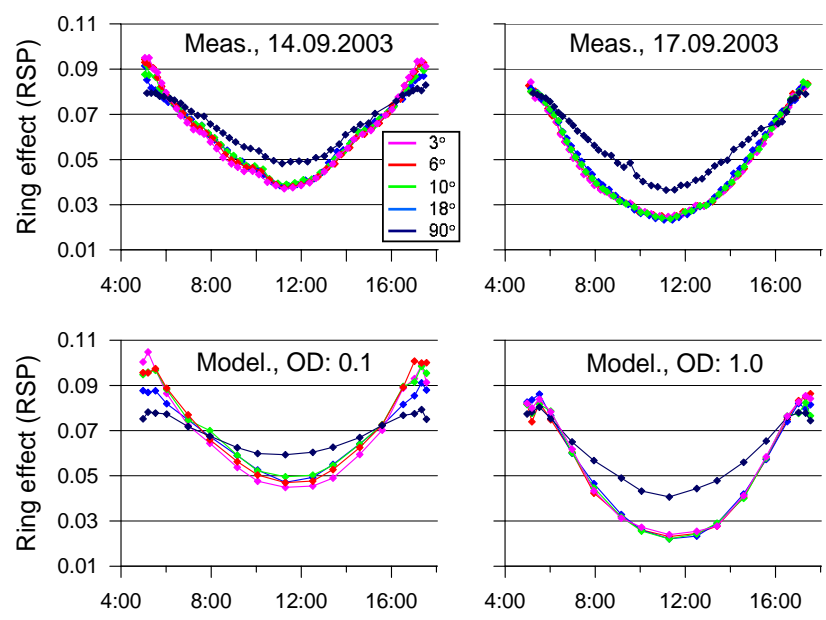

$\mathrm{O}_{4}$ absorption, southern telescope
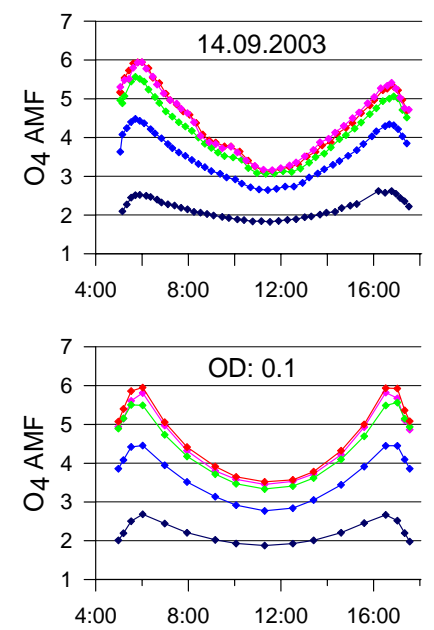

Fig. A1. Continued.
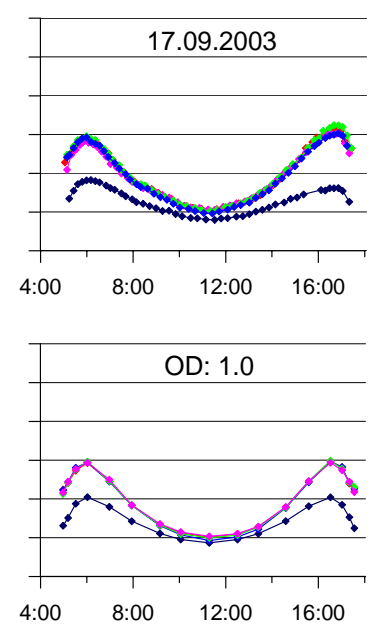

Acknowledgements. The authors would like to thank the staff of the Italian Red Cross section at the airport in Bresso (Milan), where the measurements were carried out for their great hospitality. Many thanks to Barbara Dix, Udo Frieß and Irene Pundt for their help in constructing and operating the MAX-DOAS instrument. Financial support from the EU is highly appreciated (project FORMAT, http://www.nilu.no/format/, grant EVK2-CT-2001-00120). Aerosol data from the AERONET station at Ispra (Italy) are used for comparison with our results. Many thanks to the Principal Investigator, Giuseppe Zibordi for his effort in establishing and maintaining the AERONET station at Ispra.

The service charges for this open access publication have been covered by the Max Planck Society.

Edited by: C. von Savigny

\section{Radiance, southern telescope}
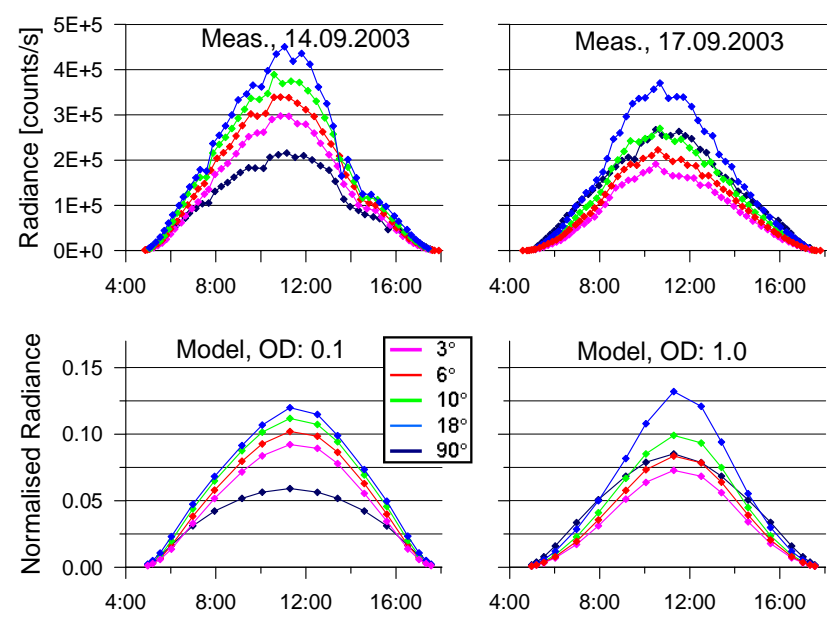

\section{Radiance ratio, southern telescope}
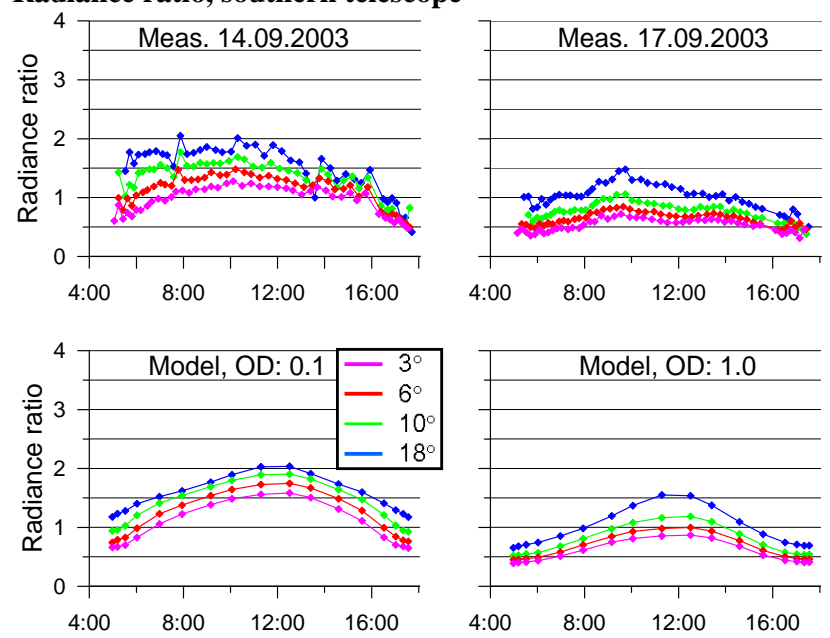

Fig. A1. Continued.

\section{References}

Aben, I., Stam, D. M., and Helderman, F.: The Ring effect in skylight polarization, Geophys. Res. Lett., 28(3), 519-522, doi:10.1029/2000GL011901, 2001.

Bobrowski, N., Hönninger, G., Galle, B., and Platt, U.: Detection of bromine monoxide in a volcanic plume, Nature, 423, 273-276, 2003.

Brinkmann, R. T.: Rotational Raman scattering in planetary atmospheres, Astrophys. J., 154, 1087-1093, 1968.

Burrows, J., Vountas, M., Haug, H., Chance, K., Marquard, L., Muirhead, K., Platt, U., Richter, A., and Rozanov, V.: Study of the Ring effect, Final Report for ESA Contract 109996/94/NL/CN, 1995.

Bussemer, M.: Der Ring-Effekt: Ursachen und Einfluß auf die Messung stratospärischer Spurenstoffe, Diploma Thesis, University of Heidelberg, 1993. 
Chance, K. V. and Spurr, R. J. D.: Ring effect studies: Rayleigh scattering, including molecular parameters for rotational Raman scattering, and the Fraunhofer spectrum, Appl. Optics, 36, 52245230, 1997.

Deutschmann, T.: Atmospheric radiative transfer modelling using Monte Carlo methods, Diploma thesis, University of Heidelberg, 2008.

Deutschmann, T. and Wagner, T.: TRACY-II Users manual, http: //joseba.mpch-mainz.mpg.de/Strahlungstransport.htm, 2008.

de Beek, R., Vountas, M., Rozanov, V. V., Richter, A., and Burrows, J. P.: The Ring effect in the cloudy atmosphere, Geophys. Res. Lett., 28, 721-724, 2001.

Erle, F., Pfeilsticker, K., and Platt, U.: On the influence of tropospheric clouds on zenith-scattered-light measurements of stratospheric species, Geophys. Res. Lett., 22, 2725-2728, 1995.

Fietkau, S., Medeke, T., Richter, A., Sheode, N., Sinnhuber, B.-M., Wittrock, F., Theys, N., van Roozendael, M., and Burrows, J. P.: Ground-based measurements of tropospheric and stratospheric bromine monoxide above Nairobi $\left(1^{\circ} \mathrm{S}, 36^{\circ} \mathrm{E}\right)$, Atmos. Chem. Phys. Discuss., 7, 6527-6555, 2007,

http://www.atmos-chem-phys-discuss.net/7/6527/2007/.

Fish, D. J. and Jones, R. L.: Rotational Raman scattering and the ring effect in zenith-sky spectra, Geophys. Res. Lett., 22, 811814, 1995.

Frieß, F., Monks, P. S., Remedios, J. J., Rozanov, A., Sinreich, R., Wagner, T., and Platt, U.: MAX-DOAS O4 measurements: A new technique to derive information on atmospheric aerosols. (II) Modelling studies, J. Geophys. Res., 111, D14203, doi:10.1029/2005JD00661, 2006.

Grainger, J. F. and Ring, J.: Anomalous Fraunhofer line profiles, Nature, 193, 762, 1962.

Greenblatt, G. D., Orlando, J. J., Burkholder, J. B., and Ravishankara, A. R.: Absorption measurements of oxygen between 330 and $1140 \mathrm{~nm}$, J. Geophys. Res., 95, 18577-18582, 1990.

Heckel, A., Richter, A., Tarsu, T., Wittrock, F., Hak, C., Pundt, I., Junkermann, W., and Burrows, J. P.: MAX-DOAS measurements of formaldehyde in the Po-Valley, Atmos. Chem. Phys., 5, 909918, 2005, http://www.atmos-chem-phys.net/5/909/2005/.

Hönninger, G. and Platt, U.: The Role of BrO and its Vertical Distribution during Surface Ozone Depletion at Alert, Atmos. Environ., 36, 2481-2489, 2002.

Hönninger, G., von Friedeburg, C., and Platt, U.: Multi axis differential optical absorption spectroscopy (MAX-DOAS), Atmos. Chem. Phys., 4, 231-254, 2004,

http://www.atmos-chem-phys.net/4/231/2004/.

Joiner, J., Bhartia, P. K., Cebula, R. P., Hilsenrath, E., McPeters, R. D., and Park, H.: Rotational Raman scattering - Ring effect in satellite backscatter ultraviolet measurements, Appl. Optics, 34, 4513-4525, 1995.

Joiner, J. and Bhartia, P. K.: The determination of cloud pressures from rotational Raman scattering in satellite backscatter ultraviolet measurements, J. Geophys. Res., 100, 23019-23026, 1995.

Joiner, J., Vasilkov, A., Flittner, D., Buscela, E., and Gleason, J.: Retrieval of Cloud Pressure from Rotational Raman Scattering, in: OMI Algorithm Theoretical Basis Document Volume III: Clouds, Aerosols, and Surface UV Irradiance, edited by: Stammes, P., ATBD-OMI-03, Version 2.0, August 2002 (http://www.knmi.nl/omi/documents/data/ OMI_ATBD_Volume_3_V2.pdf), 31-46, 2002.
Joiner, J., Vasilkov, A. P., Flittner, D. E., Gleason, J. F., and Bhartia, P. K.: Retrieval of cloud pressure and oceanic chlorophyll content using Raman scattering in GOME UV measurements., J. Geophys. Res., 109, D01109, doi:10.1029/2003JD003698, 2004.

Joiner, J. and Vasilkov, A. P.: First results from the OMI rotational Raman scattering cloud pressure algorithm, Geoscience and Remote Sensing, IEEE Transactions, 44(5), 1272-1282, 2006.

Kattawar, G. W., Young, A. T., and Humphreys, T. J.: InelasticScattering in Planetary-Atmospheres. 1. The Ring Effect, without Aerosols, Astrophys. J., 243(3), 1049-1057, 1981.

Langford, A. O., Schofield, R., Daniel, J. S., Portmann, R. W., Melamed, M. L., Miller, H. L., Dutton, E. G., and Solomon, S.: On the variability of the Ring effect in the near ultraviolet: understanding the role of aerosols and multiple scattering, Atmos. Chem. Phys., 7, 575-586, 2007, http://www.atmos-chem-phys.net/7/575/2007/.

Leser, H., Hönninger, G., and Platt, U.: MAX-DOAS measurements of $\mathrm{BrO}$ and $\mathrm{NO} 2$ in the marine boundary layer, Geophys. Res. Lett., 30, 10, doi:10.1029/2002GL015811, 2003.

Noxon, J. F., Whipple Jr., E. C., and Hyde, R. S.: Stratospheric $\mathrm{NO}_{2}$, Observational method and behavior at mid-latitude, J. Geophys. Res., 84, 5047-5076, 1979.

Park, H., Heath, D. F., and Mateer, C. L.: Possible application of the Fraunhofer line filling in effect to cloud height measurements, Meteorological Optics, OSA Technical Digest Series, 70 81, Opt. Soc. Am., Washington, D.C., 1986.

Perner, D. and Platt, U.: Absorption of light in the atmosphere by collision induced pairs of oxygen, $\left(\mathrm{O}_{2}\right)_{2}$, Geophys. Res. Lett., 7 , 1053-1056, 1980.

Platt, U., Marquard, L., Wagner, T., and Perner, D.: Corrections for zenith scattered light DOAS, Geophys. Res. Lett., 24, 1759$1762,1997$.

Platt, U. and Stutz, J.: Differential Optical Absorption Spectroscopy, Principles and Applications, Springer, Berlin, 2008.

Pfeilsticker, K., Erle, F., Funk, O., Veitel, H., and Platt, U.: First geometrical pathlengths probability density function derivation of the skylight from spectroscopically highly resolving oxygen A-band observations: 1. Measurement technique, atmospheric observations, and model calculations, J. Geophys.Res., 103, 11483-11504, 1998.

Shefov, N. N.: Spectroscopic, photoelectric, and radar investigations of the aurora and the nightglow, Izd. Akad. Nauk., 1, 25-28, 1959.

Sioris, C. E. and Evans, W. F. J.: Impact of rotational Raman scattering in the $\mathrm{O}_{2} \mathrm{~A}$ band, Geophys. Res. Lett., 27, 4085-4088, 2000.

Solomon, S., Schmeltekopf, A. L., and Sanders, R. W.: On the interpretation of zenith sky absorption measurements, J. Geophys. Res., 92, 8311-8319, 1987.

Theys, N., Van Roozendael, M., Hendrick, F., Fayt, C., Hermans, C., Baray, J.-L., Goutail, F., Pommereau, J.-P., and De Mazire, M.: Retrieval of stratospheric and tropospheric BrO columns from multi-axis DOAS measurements at Reunion Island $\left(21^{\circ} \mathrm{S}\right.$, $56^{\circ}$ E), Atmos. Chem. Phys., 7, 4733-4749, 2007, http://www.atmos-chem-phys.net/7/4733/2007/.

van Deelen, R., Hasekamp, O. P., van Diedenhoven, B., and Landgraf, J.: Retrieval of cloud properties from near ultraviolet, visible and near infrared satellite-based Earth reflectance spectra: a comparative study, J. Geophys. Res., 113, D12204, 
doi:10.1029/2007JD009129, 2008.

Van Roozendael, M., Fayt, C., Post, P., Hermans, C., and Lambert, J.-C.: Retrieval of $\mathrm{BrO}$ and $\mathrm{NO}_{2}$ from UV-Visible Observations, in: Sounding the troposphere from space: a new era for atmospheric chemistry, Springer-Verlag, ISBN 3-540-40873-8, edited by: Borrell, P., Borrell, P. M., Burrows, J. P., and Platt, U., 2003.

Volkamer, R.: Absorption von Sauerstoff im Herzberg I system, und Anwendungen auf die Aromatenmessungen am EUropean PHoto REactor, (EUPHORE), Diploma thesis, University of Heidelberg, Germany, 1996.

Vountas, M.: Die Modellierung und Parametrisierung des Ring Effektes: Einfluß auf die Bestimmung von stratosphärischen Spurengasen, PhD-thesis, University of Bremen, http://www.iup. physik.uni-bremen.de/diss/Vountas/ring_diss/master.html, 1998.

Vountas, M., Rozanov, V. V., and Burrows, J. P.: Ring effect: Impact of rotational Raman scattering on radiative transfer in earth's atmosphere, J. Quant. Spectrosc. Radiat. Trans., 60(6), 943-961, 1998.

Wagner, T., Erle, F., Marquard, L., Otten, C., Pfeilsticker, K., Senne, T., Stutz, J., and Platt, U.: Cloudy sky optical paths as derived from differential optical absorption spectroscopy observations, J. Geophys. Res., 103, 25307-25321, 1998.

Wagner, T., von Friedeburg, C., Wenig, M., Otten, C., and Platt, U.: UV/vis observations of atmospheric $\mathrm{O}_{4}$ absorptions using direct moon light and zenith scattered sunlight under clear and cloudy sky conditions, J. Geophys. Res., 107, 4424, doi:10.1029/2001JD001026, 2002.

Wagner, T., Dix, B., v. Friedeburg, C., Frieß, U., Sanghavi, S., Sinreich, R., and Platt, U.: MAX-DOAS O4 measurements a new technique to derive information on atmospheric aerosols. (I) Principles and information content, J. Geophys. Res., 109, D22205, doi:10.1029/2004JD004904, 2004.
Wagner, T., Burrows, J. P., Deutschmann, T., Dix, B., von Friedeburg, C., Frieß, U., Hendrick, F., Heue, K.-P., Irie, H., Iwabuchi, H., Kanaya, Y., Keller, J., McLinden, C. A., Oetjen, H., Palazzi, E., Petritoli, A., Platt, U., Postylyakov, O., Pukite, J., Richter, A., van Roozendael, M., Rozanov, A., Rozanov, V., Sinreich, R., Sanghavi, S., and Wittrock, F.: Comparison of box-airmass-factors and radiances for Multiple-Axis Differential Optical Absorption Spectroscopy (MAX-DOAS) geometries calculated from different UV/visible radiative transfer models, Atmos. Chem. Phys., 7, 1809-1833, 2007a, http://www.atmos-chem-phys.net/7/1809/2007/.

Wagner, T., Ibrahim, O., Sinreich, R., Frie, U., von Glasow, R., and Platt, U.: Enhanced tropospheric BrO over Antarctic sea ice in mid winter observed by MAX-DOAS on board the research vessel Polarstern, Atmos. Chem. Phys., 7, 3129-3142, 2007b, http://www.atmos-chem-phys.net/7/3129/2007/.

Wagner, T., Beirle, S., and Deutschmann, T.: Three-dimensional simulation of the Ring effect in observations of scattered sun light using Monte Carlo radiative transfer models, Atmos. Meas. Tech., 2, 113-124, 2009, http://www.atmos-meas-tech.net/2/113/2009/.

Wittrock, F., Oetjen, H., Richter, A., Fietkau, S., Medeke, T., Rozanov, A., and Burrows, J. P.: MAX-DOAS measurements of atmospheric trace gases in Ny-Ålesund - Radiative transfer studies and their application, Atmos. Chem. Phys., 4, 955-966, 2004, http://www.atmos-chem-phys.net/4/955/2004/. 